\title{
The complete chloroplast genomes of three Betulaceae species: implications for molecular phylogeny and historical biogeography
}

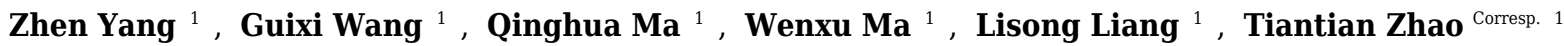 \\ ${ }^{1}$ Key Laboratory of Tree Breeding and Cultivation of the State Forestry and Grassland Administration, Research Institute of Forestry, Chinese Academy of \\ Forestry, Beijing, China \\ Corresponding Author: Tiantian Zhao \\ Email address: zhaotian1984@163.com
}

Background. Previous phylogenetic conclusions on the family Betulaceae were based on either morphological characters or traditional single loci, which may indicate some limitations. Chloroplast genome contains rich polymorphism information, which is very suitable for phylogenetic studies. Thus, we sequenced the chloroplast genome sequences of three Betulaceae species and performed multiple analyses to investigate the genome variation, resolve the phylogenetic relationships, and clarify the divergence history.

Methods. Chloroplast genomes were sequenced using the high-throughput sequencing. A comparative genomic analysis was conducted to examine the global genome variation and screen the hotspots. Three chloroplast partitions were used to reconstruct the phylogenetic relationships using Maximum Likelihood and Bayesian Inference approaches. Then, molecular dating and biogeographic inferences were conducted based on the whole chloroplast genome data.

Results. Betulaceae chloroplast genomes consisted of a small single-copy region and a large single copy region, and two copies of inverted repeat regions. Nine hotspots can be used as potential DNA barcodes for species delimitation. Phylogenies strongly supported the division of Betulaceae into two subfamilies: Coryloideae and Betuloideae. The phylogenetic position of Ostryopsis davidiana was controversial among different datasets. The divergence time between subfamily Coryloideae and Betuloideae was about 70.49 Mya, and all six extant genera were inferred to have diverged fully by the middle Oligocene. Betulaceae ancestors were probably originated from the ancient Laurasia.

Discussions. This research elucidates the potential of chloroplast genome sequences in the application of developing molecular markers, studying evolutionary relationships and historical dynamic of Betulaceae. It also reveals the advantages of using chloroplast genome data to illuminate those phylogenies that have not been well solved yet by traditional approaches in other plants. 


\title{
1 The complete chloroplast genomes of three
}

\section{Betulaceae species: implications for molecular}

3 phylogeny and historical biogeography

4

5

6

7

8
9

\begin{abstract}
Zhen Yang, Guixi Wang, Qinghua Ma, Wenxu Ma, Lisong Liang, Tiantian Zhao*
\end{abstract}
Key Laboratory of Tree Breeding and Cultivation of the State Forestry and Grassland Administration, Research Institute of Forestry, Chinese Academy of Forestry, Beijing, China

Corresponding Author:

Tiantian Zhao

No. 1, dongxiaofu, xiangshan road, haidian district, Beijing, 100091, China

Email address: zhaotian1984@163.com

\section{ABSTRACT}

Background. Previous phylogenetic conclusions on the family Betulaceae were based on either morphological characters or traditional single loci, which may indicate some limitations. Chloroplast genome contains rich polymorphism information, which is very suitable for phylogenetic studies. Thus, we sequenced the chloroplast genome sequences of three Betulaceae species and performed multiple analyses to investigate the genome variation, resolve the phylogenetic relationships, and clarify the divergence history.

Methods. Chloroplast genomes were sequenced using the high-throughput sequencing. A comparative genomic analysis was conducted to examine the global genome variation and screen the hotspots. Three chloroplast partitions were used to reconstruct the phylogenetic relationships using Maximum Likelihood and Bayesian Inference approaches. Then, molecular dating and biogeographic inferences were conducted based on the whole chloroplast genome data.

Results. Betulaceae chloroplast genomes consisted of a small single-copy region and a large single copy region, and two copies of inverted repeat regions. Nine hotspots can be used as potential DNA barcodes for species delimitation. Phylogenies strongly supported the division of Betulaceae into two subfamilies: Coryloideae and Betuloideae. The phylogenetic position of Ostryopsis davidiana was controversial among different datasets. The divergence time between subfamily Coryloideae and Betuloideae was about 70.49 Mya, and all six extant genera were inferred to have diverged fully by the middle Oligocene. Betulaceae ancestors were probably originated from the ancient Laurasia.

Discussions. This research elucidates the potential of chloroplast genome sequences in the application of developing molecular markers, studying evolutionary relationships and historical dynamic of Betulaceae. It also reveals the advantages of using chloroplast genome data to 
38 illuminate those phylogenies that have not been well solved yet by traditional approaches in 39 other plants.

\section{INTRODUCTION}

41 The family Betulaceae in the order Fagales consist of approximately 100 150 species of trees

42

43

44

45

46

47

48

49

50

51

52

53

54

55

56

57

58

59

60

61

62

63

64

65

66

67

68

69

70

71

72

73

74

75

76

77 and shrubs that distributed in the temperate zone of the Northern Hemisphere, with a few species spreading to South America and only one species (Alnus glutinosa (L.) Gaertn) occurring in Africa (Kubitzki et al., 1993). This family is well-defined to contain six genera, five of which (Betula, Alnus, Corylus, Ostrya, and Carpinus) display similar patterns of intercontinental disjunction between Eurasia and North America, whereas Ostryopsis is only endemic to China. The typical features of Betulaceae are their doubly serrate, stipulate leaves, small winged fruits or nuts associated with leafy husks, and catkins appear before leaves.

The monophyly of Betulaceae is supported by numerous synapomorphies, such as compound catkins (Abbe, 1974), pollen micromorphology (Chen, 1991), growth habitat (Kikuzawa, 1982), and embryology (Xing et al., 1998). However, the generic relationships within the family have subjected to various controversies. In previous studies, both morphological taxonomy and molecular phylogenies have generally recognized two main lineages in Betulaceae, treated either as two tribes (Coryleae and Betuleae) (Bousquet et al., 1992; Crane, 1989) or two subfamilies (Coryloideae and Betuloideae) (Furlow, 1990; Bousquet et al., 1992; Chen et al., 1999; Forest et al., 2005). Meanwhile, some other taxonomists upgraded the two lineages as two families Corylaceae and Betulaceae sensu stricto (Dahlgren, 1983; Hutchinson, 1967). Recent treatments (Xiang et al., 2014; Grimm and Renner, 2013; Soltis et al., 2011), including the Angiosperm Phylogeny Group (APG III, 2009; APG IV, 2016), also have described the two lineages as subfamilies within an expanded Betulaceae: Betuloideae (Betula and Alnus) and Coryloideae (Ostryopsis, Corylus, Ostrya, and Carpinus). Nevertheless, all the above taxonomic and phylogenetic conclusions are inferred from unreliable and dynamic morphological features or DNA fragments with limited polymorphic information loci (e.g., $r b c \mathrm{~L}$, matK, and ITS), which may inevitably bias the phylogenetic reference (Philippe et al., 2011). Especially, due to recent speciation and rapid diversification, the generic relationships within the subfamily Coryloideae are still phylogenetically and taxonomically difficult (Forest et al., 2005; Yoo and Wen, 2002; Chen et al., 1999; Kato et al., 1998). Additionally, future studies on Betulaceae will pay more attention to species identification, population genetics, and biogeographic origin. All these studies rely on high-resolution molecular markers and robust phylogeny, but the limited and low-resolution DNA markers heavily inhibited the comprehensive evaluation of Betulaceae resources. Therefore, it is imperative to develop efficient molecular markers to resolve the current problems.

Chloroplast (cp) genome is one of the three sets of genetic systems (cytoblast, chloroplast, and mitochondrion) with different evolutionary histories and origins in higher plants. Generally, phylogenetic inferences using nuclear genomes are unrealistic for their costly situation and lack of enough genomic data (Wang et al., 2014; Olsen et al., 2016). Meanwhile, mitochondrial genomes are not suitable for phylogenetic studies of plants due to their slow evolutionary rate 
78

79

80

81

82

83

84

85

86

87

88

89

90

91

92

93

94

95

96

97

98

99

100

101

102

103

104

105

106

107

108

109

110

111

112

113

114

115

116

117

and rich in exogenous sequences (Palmer and Herbon, 1988). Compared to nuclear and mitochondrial genomes, cp genomes have independent evolutionary routes and own the characteristics of uniparental inheritance, moderate rates of nucleotide substitutions, haploid status, and no homologous recombination (Hansen et al., 2007; Shaw et al., 2005). Correspondingly, these features of $\mathrm{cp}$ genomes make them particularly suitable for phylogenetic and biogeographic studies of plants (Attigala et al., 2016; Walker et al., 2014; Huang et al., 2014). With the accumulation of angiosperm cp genomes, comparative genomics and phylogenomics of closely related cp genomes are very useful for grasping the genome evolution regarding structure variations, nucleotide substitutions, and gene losses (Hu et al., 2017; Raman et al., 2016; Barrett et al., 2016). Meanwhile, lots of high-resolution genetic markers, such as intergenic spacer (IGS) fragments (Liu et al., 2017), simple sequence repeats (SSRs) (Huang et al., 2014), single nucleotide polymorphisms (SNPs) (Li et al., 2014), and repeated sequences (Provan et al., 2001) were identified across the cp genomes and applied for multi-aspect studies in different plant taxa.

Currently, the cp genomic resources of Betulaceae are fairly limited, and much less for some rare species from the genera Corylus and Alnus. Especially, no cp genome is available for the genus Ostryopsis. Here, we sequenced the complete cp genome sequences of three Chinese endemic Betulaceae species (Ostryopsis davidiana, Corylus wangii, and Alnus cremastogyne) that are narrowly distributed in limited regions and are poorly studied in previous research, then, comparative genomics and phylogenomics analyses were conducted by integrating previously published $\mathrm{cp}$ genomes from other taxa in Betulaceae. Our aims are to compare and characterize the cp genomes among selected species of Betulaceae; identify and screen molecular markers suitable for population genetics; reconstruct the intergeneric relationships of the six extant genera of Betulaceae; estimate the divergence time and biogeographic history of Betulaceae.

\section{MATERIALS \& METHODS}

\section{Plant materials, DNA isolation and sequencing}

Fresh plant leaves of three Betulaceae species were harvested from their natural populations in China, including Ostryopsis davidiana from Chifeng, Neimengu, Corylus wangii from Weixi, Yunnan, and Alnus cremastogyne from Wuxi, Chongqing. Voucher specimens were stored in herbaria of Research Institute of Forestry, Chinese Academy of Forestry. Total genomic DNA was extracted from silica-dried leaves using a modified CTAB protocol (Li et al., 2013) and purified employing the Wizard DNA CleanUp System (Promega, Madison, WI, USA). DNA samples were fragmented randomly and then were sheared into 400-600 bp fragments through agarose gel electrophoresis. The paired-end libraries with $500 \mathrm{bp}$ insert size were built using the Illumina PE DNA library kit, and then paired reads were sequenced with an Illumina HiSeq 4000-PE150.

\section{Chloroplast genome assembly and annotation}

We used SPAdes 3.6.1 (Bankevich et al., 2012) to initially assemble the cp genomes under the 'careful' option with k-mer sizes of 21, 33, 55, 77 and 89. SPAdes contigs were further blasted against the Corylus heterophylla (KX822769) and Alnus alnobetula (MF136498) cp genomes 
118 using blastn with an e value cutoff of $1 \mathrm{e}^{-10}$ to filter out chloroplast-like contigs (Camacho et al., 119 2009). Then, these chloroplast contigs were assembled using Sequencher v5.4 software. Finally, 120 Geneious 8.1 (Kearse, et al., 2012) was used to map all the reads onto the assembled chloroplast

121

122

123

124

125

126

127

128

129

130

131

132

133

134

135

136

137

138

139

140

141

142

143

144

145

146

147

148

149

150

151

152

153

154

155

156

157

genome to verify the accuracy. Based on the reference sequence, the junctions among large single copy (LSC) region, two inverted repeat (IRa and IRb) regions, and small single copy (SSC) region were verified following the method of Dong et al (2014). Annotations of the three chloroplast genomes were performed using the online program DOGMA (Wyman et al., 2004) with default parameters. Positions of introns, starts, and stops were checked by aligning with homologous genes of Corylus heterophylla (KX822769) and Alnus alnobetula (MF136498) cp genomes using MAFFT v7.0.0 (Katoh and Standley, 2013). In addition, annotations of transfer RNAs were further verified with tRNAscan-SE search server (Schattner et al., 2005). The cp genome map was plotted with Genome Vx software (Conant and Wolfe, 2008). The annotated cp genome sequences of Ostryopsis davidiana, Corylus wangii, and Alnus cremastogyne have been submitted to GenBank (accession Number: MH628451, MH628454, and MH628453).

\section{Comparative analysis and sequence divergence}

In order to evaluate the sequence divergence of Betulaceae cp genomes, we randomly selected six of the available Betulaceae species (one representative for each of the six genera), including three cp genomes we reported here plus the cp genomes of Carpinus tientaiensis (KY174338), Betula nana (KX703002), and Ostrya rehderiana (KT454094). Based on previous studies, the contraction and expansion of IR regions could bring about the structure variation and length change of cp genomes (Nazareno et al., 2015; Yang et al., 2018). Thus, we performed a comparative analysis to test the variation in the IR/SC junctions among Betulaceae cp genomes. To assess rearrangement and substantial sequence divergence, we conducted a synteny analysis using the progressive Mauve aligner implemented in Mauve 2.3.1 (Darling et al., 2010) under default settings. To screen polymorphic hotspots that can be used as molecular markers to identify Betulaceae species, 79 shared protein-coding genes (PCG) and 121 intergenic spacer regions (IGS) of the six cp genomes were separately extracted. These homologous regions were aligned using MAFFT 7.0 and then adjusted manually with Se-Al 2.0 (Rambaut, 1996). Subsequently, the number of variable sites and aligned sequence length for each region was calculated using DnaSP 5.0 (Librado and Rozas, 2009), and the percentages of variable sites = (number of variable sites/aligned sequence length) $\times 100$.

\section{Repeated sequences and microsatellites}

We employed the online REPuter software (Kurtz et al., 2001) to scan and visualize forward, reverse, complement, and palindromic structure with a minimum repeat size of $30 \mathrm{bp}$ and edit distances of less than $3 \mathrm{bp}$. Tandem repeats were identified using the online software Tandem Repeats Finder 4.07 b (Benson, 1999), with the match, mismatch, and indel parameters separately set as $2,7,7$. The minimum alignments score and maximum period size were assigned 70 and 500, respectively. Microsatellites or simple sequence repeats (SSRs) were predicted with Msatcommander 0.8.2 (Faircloth, 2008). We set the threshold for mono-, di-, tri-, tetra-, penta-, and hexa-nucleotide SSRs with ten, five, four, three, three, and three repeat units, respectively. 


\section{Phylogenetic inference}

159 In order to infer the intergeneric relationships within Betulaceae, eleven representative cp 160 genome sequences from the six genera (Betula, Alnus, Corylus, Carpinus, and Ostrya) of 161 Betulaceae were applied to construct phylogenetic trees, with two species from the genus 162 Juglans (Juglans regia and Juglans nigra) selected as outgroup taxa. These cp genomes and 163 GenBank accession numbers are listed in Table S1. To evaluate the utility of different structural 164 domains, phylogenies were inferred based on three datasets: (1) complete cp genome sequences 165 (CPG); (2) protein-coding genes (PCG); (3) intergenic spacer regions (IGS). Each dataset was 166 aligned using MAFFT 7.0 with default parameters and ambiguously aligned sites in all 167 alignments were removed using Gblocks v.0.91b (Talavera and Castresana, 2007) with all gap 168 positions allowed. Two different phylogenetic algorithms were employed in this analysis: Maximum likelihood (ML) method and Bayesian inference (BI) method. We conducted the ML analysis using IQ-tree 1.6.3 (Nguyen et al., 2015) with 1000 replicates of ultrafast bootstrapping (UFBoot) (Minh et al., 2013) and 1000 bootstrap replicates of the Shimodaira/Hasegawa approximate likelihood-ratio test (SH-aLRT) (Guindon et al., 2010). The best-fit model for each sequence partition was predicted by the built-in ModelFinder program (Kalyaanamoorthy et al., 2017) of IQ-tree under the Bayesian information criterion. TVM+F+R3, TVM+F+I, and $\mathrm{GTR}+\mathrm{F}+\mathrm{R} 2$ substitution models were selected for CPG, PCG, and IGS, respectively. BI analysis was performed using MrBayes 3.2.6 (Ronquist et al., 2012) under GTRGAMMA model, with four chains and two parallel runs. Each run was conducted until completion, and included $1,000,000$ generations, with sampling every 100 generations. The first $25 \%$ of the trees were discarded as burn-in and the remaining trees were used for generating the consensus tree. The final trees and posterior probabilities were visualized with FigTree v1.4 (Rambaut, 2012).

\section{Molecular dating analysis}

We performed a time-calibrated coalescent Bayesian analysis in BEAST 2.48 (Bouckaert et al., 2014) to estimate the divergence times of Betulaceae lineages at genus level. BEAST is a crossplatform program for Bayesian analysis of molecular sequences using Markov chain Monte Carlo (MCMC). It is entirely orientated towards rooted, time-measured phylogenies inferred using strict or relaxed molecular clock models. In this study, we estimated divergence times using a gamma-distributed rate variation, a proportion of invariant sites of heterogeneity model, and estimated base frequencies. An uncorrelated log-normal clock was applied with a Yule process speciation prior for branching rates. Two fossil constraints were used for calibration: (1) the crown age of the family Betulaceae was set to 69.95 Mya $(\mathrm{SD}=2.0)$ and assigned a normal distribution (Xiang, 2014); (2) A prior for the calibration of the most recent common ancestor (MRCA) for the subfamily Coryloideae was included following a normal distribution with mean 48 Mya ( $\mathrm{SD}=0.5)$ (Pigg et al., 2003). We ran 500 million MCMC generations with a sampling frequency of 1000 generations after a burn-in of $1 \%$. The convergence of parameters was greater than 200. Maximum clade credibility (MCC) trees were computed after discarding $1 \%$ of the respective saved trees as burn-in. 
198

199

200

201

202

203

204

205

206

207

208

209

210

211

212

213

214

215

216

217

218

219

220

221

222

223

224

225

226

227

228

229

230

231

232

233

234

235

236

237

\section{Ancestral area reconstruction}

To grasp the biogeographical history of Betulaceae, we performed an ancestral area reconstruction. Six areas were designated based on the tectonic history of continents and the current distribution data of Betulaceae species: $\mathrm{A}=$ East Asia; $\mathrm{B}=$ Europe; $\mathrm{C}=$ North America; $\mathrm{D}=$ Central America; $\mathrm{E}=$ South America; $\mathrm{F}=$ North Africa. Based on the MCC tree obtained from BEAST, the Bayesian binary MCMC (BBM) method in RASP 4.0 (Yu et al., 2015) was used to reconstruct the ancestral areas of Betulaceae species. MCMC chains in the BBM analysis were run for 10 million generations with a sampling frequency of 100, discarding the first 1,000 generations as burn-in. The number of maximum areas was maintained at four.

\section{RESULTS}

\section{Chloroplast genome sequencing and assembly}

Using the Illumina HiSeq 4000-PE150 platform, we newly sequenced the cp genomes of three Betulaceae species (Ostryopsis davidiana, Corylus wangii, and Alnus cremastogyne). Overall, Illumina paired-end $(2 \times 150 \mathrm{bp})$ sequencing generated large datasets for each species, with 8,683,726 (Ostryopsis davidiana), 22,450,682 (Corylus wangii), and 27,361,376 (Alnus cremastogyne) paired-end reads mapped to the reference genome sequences, resulting $777 \times, 132$ $\times$, and $785 \times$ coverage across the three $\mathrm{cp}$ genomes. The results indicated that the quality of $\mathrm{cp}$ genome sequencing and assembly was very high.

\section{Organization of Betulaceae chloroplast genome}

The availability of three other complete $\mathrm{cp}$ genomes of Betulaceae species (Carpinus tientaiensis, KY174338; Betula nana, KX703002.1; Ostrya rehderiana, KT454094) provided an opportunity to compare the cp genome organization and sequence variation within this family. Organization of the Betulaceae cp genome was quite conserved; neither inversions nor translocations were observed in the analysis. The six cp genomes ranged from 159,286 base pairs (bp) (Ostryopsis davidiana) to 160,579 bp (Betula nana) in length. The six cp genomes displayed a circular quadripartite structure including two IR regions (ranging from 25,927 bp in Ostrya rehderiana to 26,185 bp in Alnus cremastogyne), the LSC region (ranging from 88,552 bp in Ostrya rehderiana to $89,493 \mathrm{bp}$ in Betula nana), and the SSC region (18,588 in Ostryopsis davidiana to 19,094 bp in Alnus cremastogyne) (Table 1, Fig. 1). Differences in genome size mainly resulted from the length variation of the SC regions, with minor discrepancies observed among IR regions. The GC content was roughly identical among the six cp genomes, ranging from 36.07 to $36.68 \%$.

Each of the six Betulaceae cp genomes encoded 131 genes, of which 113 genes were unique, and 18 genes were repeated in the two IRs (Table 1). These genes included 79 proteincoding genes, 30 tRNA genes, and four rRNA genes (Table 2). Notably, the rps 12 gene was annotated to be trans-spliced with the 3' end duplicated in IRa and IRb, and the single 5' end exon located in LSC. By comparison, the six cp genomes are uniform in gene order, gene content, and proportion of coding and non-coding regions. Accordingly, the annotated genomes were represented by one genome map (Fig. 1). Most protein-coding genes comprised only one exon, while ten genes (atpF, rpoCl, rpl2, ndhA, ndhB, ndhK, trnV-UAC, trnI-GAU, trnA-UGC, 
238 and $\operatorname{trnL}-U A A)$ were found to have one intron, and two genes ( $\operatorname{clpP}$ and $y c f 3$ ) contained two 239 introns each (Table 2). The majority of the above genes were distributed in LSC and IRs, with 240 only one gene (ndhA) located in SSC.

\section{IR contraction and expansion}

242 To illuminate the putative contraction and expansion of IR regions, we investigated the gene 243 variation at the IR/SC boundary regions of the six cp genomes (Fig. 2). At the IRa/LSC 244 junctions, the gene rps 19 of $O$. davidiana and $C$. wangii crossed the IRa/LSC border, while $245 r$ rps 19 and rpl2 of A. cremastogyne, C. tientaiensis, and B. nana were located in the two sides of 246 this border, and gene $r p l 2$ was created at the IRa/LSC border of $O$. rehderiana. The IRa/SSC 247 junctions were inserted into the gene $y c f 1$ in three cp genomes, with $1 \mathrm{bp}($ O. davidiana), $3 \mathrm{bp}(\mathrm{C}$. 248 tientaiensis), and 155 bp (B. nana) located in the SSC region, respectively; with regard to $A$. 249 cremastogyne and $C$. wangii, $y c f l$ and $n d h F$ were seated on either side of the junction; notably, 250 the $n d h F$ gene extended $72 \mathrm{bp}$ into IRa region in $O$. rehderiana. In all the six cp genomes, the 251 $y c f 1$ gene crossed the IRb/SSC boundary regions, resulting in the incomplete duplication of this gene in two IRs. The gene rpl22 and trnH-GUG gene were distributed in the two sides of the $\mathrm{IRb} / \mathrm{LSC}$ junction, with 0-82 bp for rpl22 and 1-88 bp for $\operatorname{trn} H-G U G$ away from the junctions,

254

255

256

257

258

259

260

261

262

263

264

265

266

267

268

269

270

271

272

273

274

275

276

277

respectively. IR contraction and expansion in the six Betulaceae cp genomes ultimately lead to the length variations of the four structural segments and whole genome sequences.

\section{Synteny analysis and divergence hotspots}

In accordance with the alignment results, all the six cp genomes showed the same order and orientation of syntenic blocks (Fig. 3), indicating that Betulaceae cp genomes tend to be conserved and highly collinear, especially at the genus level. Nevertheless, a few local changes representing variable regions were still detected, with several obvious divergence fragments mainly located in SC regions, especially within the nucleotide sequences of 5,000-20,000 bp, 25,000-35,000 bp, and 135,000-145,000 bp. By contrast, the IR regions were quite conserved and no significant sequence divergence was found. Furthermore, in order to locate mutation hotspots, the variable percentages of PCG and IGS regions were calculated and analyzed (Fig. 4; Table S2). In total, cp genomes of the six Betulaceae species exhibited 7830 (5.99\%) variable sites in the 130,710 sites analyzed, of which the average variable percentage of coding regions and intergenic spacers was $2.77 \%$ and $9.65 \%$, respectively. The SSC region showed the highest variable percentage (9.41\%), followed by the LSC region (6.56\%), and then IR region $(1.15 \%)$. Finally, nine hotspots (percentage of variable sites $>20 \%$ ) were screened in the intergenic regions, they were: $y c f 1-n d h F, \operatorname{trnG-trnR,~trnH-psbA,~rps19-rpl2,~rps16-trnQ,~atpA-atpF,~ndhC-}$ trnV, $n d h F-r p l 32$, and $r p l 32-t r n L$. Among them, five fragments were distributed in LSC, two in $\mathrm{SSC}$, and two crossed the IRa/LSC and IRa/SSC boundary regions.

\section{Repeated sequences and SSRs}

In the present study, four sorts of repeated sequences (forward, reverse, palindromic, and tandem) were detected in the three newly sequenced cp genomes (Fig. 5A, 5B; Table S3, S4). Overall, 30 forward repeats, 24 palindromic repeats, 3 reverse repeats, and 27 tandem repeats were identified in $O$. Davidiana cp genome. In $C$. wangii cp genome, the numbers of these four 
278 repeats were 19,21, 1, and 18, respectively. By contrast, only 29 forward repeats and 27 tandem 279 repeats were predicted in A. cremastogyne cp genome. The lengths of dispersed repeats (forward, 280 palindromic, and reverse) ranged from 30 to $194 \mathrm{bp}$, with most of them centered on 30-45 bp 281 (82.68\%), while those of 45-60 bp (2.36\%), 60-75 bp (1.57\%), and 75-90 bp (3.15\%) were 282 relatively rare. The lengths of tandem repeats varied from 8 to $123 \mathrm{bp}$, of which a large 283 proportion of them centered on 0-19 bp and 20-39 bp. Repeat sequences were mainly located in 284 the non-coding regions, including IGS and introns. In addition, a few of coding genes (e.g., $y c f 2$, $285 y c f 3, p s a A$, atpA, and $p s a B$ ), tRNAs (e.g., $\operatorname{trn} S-G G A, \operatorname{trn} S$-GCU), and rRNA (e.g., $r r n 16$ ) were 286 also found to contain repeat structure.

287

288

289

290

291

292

293

294

295

296

297

298

299

300

301

302

303

304

305

306

307

308

309

310

311

312

313

314

315

316

317

Six types of SSRs (mono-, di-, tri-, tetra-, penta-, and hexa-nucleotide) were scanned within these cp genomes (Fig. 5C, 5D; Table S5). In total, 67-86 SSRs were detected, of which mononucleotides (especially $\mathrm{A} / \mathrm{T}$ ) were the most abundant, with the number ranging from 38 in $\mathrm{A}$. cremastogyne to 56 in $C$. wangii. Di-nucleotides (especially AT) were the second most predominant, varying for 10 in $O$. davidiana and 15 in both A. cremastogyne and C. wangii. Furthermore, our data disclosed that tetra-nucleotides which included seven sorts of sequence repeats were the most abundant SSR type, although their numbers were few. Simultaneously, a small number of tri-nucleotides were also discovered in all three cp genomes. However, only very few penta and hexa-nucleotides were detected, with one penta-nucleotide (AAAAT) and one hexa-nucleotide (AATTTT) existed in A. cremastogyne, and one hexa-nucleotide (CTAGTT) in O. davidiana. SSRs were chiefly located in non-coding regions (particularly IGS), while some coding genes (e.g., $p s b I, r p o C 2, r p o B, a t p F$, and $a t p B$ ) were also found to hold SSRs. On the whole, SSRs were unevenly scattered throughout the four structural domains of $\mathrm{cp}$ genomes, with most of them distributed in LSC, followed by SSC and IR.

\section{Phylogenetic inference}

Both the ML and BI phylogenies inferred from CPG and PCG datasets displayed nearly identical topologies in identifying the taxonomic status of six genera (Fig. 6A, S1). All the nodes were moderately or highly supported. The eleven ingroup taxa were divided into two major clades, which accorded well with traditionally divided Coryloideae and Betuloideae. The subfamily Coryloideae was a large clade constituted by four genera (Corylus, Ostryopsis, Carpinus, and Ostrya), while Betuloideae consisted of the other two genera (Betula and Alnus), of which Carpinus-Ostrya and Alnus-Betula formed two stable sister subclades. The two Juglans species were included in outgroup. Although the intergeneric relationships revealed by IGS data were mostly consistent with that of CPG and PCG datasets, visible incongruence on the phylogenetic position of Ostryopsis was still observed. The CPG and PCG phylogenies placed Ostryopsis basal to the Carpinus-Ostrya subclade (Fig. 6A, S1), while the IGS phylogeny supported it sister to Corylus (Fig. 6B).

\section{Divergence times and ancestral areas}

The tree topology inferred from the molecular dating analysis (Fig. 7) was consistent with those recovered from CPG and PCG datasets (Fig. 6A, S1). All the nodes in the tree were highly supported with a posterior probability of 1 . The estimated divergence time and $95 \%$ highest 
318 posterior density (HPD) were displayed on the branches. Betuloideae and Coryloideae diverged 319 in the late Cretaceous ( 70.49 Mya, $95 \%$ HPD $=66.62-74.29$ Mya), as their most probable time of 320 origin. The divergence of Betuloideae into Betula and Alnus occurred in the middle Paleocene 321 ( $\sim 61.76$ Mya, 95\% HPD=49.77-70.97 Mya). The MRCA of Coryloideae and the split of Corylus 322 occurred in the early Eocene (47.93 Mya, 95\% HPD=46.95-48.91 Mya). The divergence time 323 between the genus Ostryopsis and the sister group of Ostrya-Carpinus was around 44.63 Mya 324 (95\% HPD=40.11-47.93 Mya), which was a little later than Corylus ( 3 Mya). The 325 diversification of the sister subclade (Ostrya and Carpinus) was suggested to be $26.73 \mathrm{Mya}$ ( $95 \%$ $326 \mathrm{HPD}=15.09-39.44 \mathrm{Mya})$ in the late Oligocene. BBM analysis suggests that intercontinental

327

328

329

330

331

332

333

334

335

336

337

338

339

340

341

342

343

344

345

346

347

348

349

350

351

352

353

354

355

356

357

dispersals played important roles in the biogeographic history of Betulaceae (Fig. 8). However, the origin area of the six extant genera was unclear because of the insufficient species sampling, and uncertainty of its sister group in previous studies. In spite of this, we identified three major distribution areas: East Asia (A), Europe (B), and North America (C) which were speculated to break away and drift from the old Laurasia in the Paleozoic ( 57-23 Mya). The extant species of three genera (Alnus, Ostrya, and Carpinus) that exist in Central America (D) and South America (E) may have originated in North America (C) and traveled across the Isthmus of Panama to South America. While a few Alnus species have spanned the island chains constituted by Balkan Peninsula, Southern Turkey, and Italy into North Africa (F).

\section{DISCUSSION}

In the research, we characterized the cp genomes of three Betulaceae species, identified SSRs, repeated sequences, divergence hotspots throughout these genomes, and performed phylogenetic analyses by integrating closely related cp genomes. Correspondingly, these findings also provide an opportunity to explore the divergence history of Betulaceae species. Our research has laid the foundation for future studies on the evolution of Ostryopsis, Alnus, and Corylus, as well as the molecular identification of Betulaceae species.

\section{Chloroplast genome variation and evolution}

The cp genomes of most angiosperms are validated to contain approximately 130 genes, of which about 20 genes have two copies in two IRs, leaving the rest 110 being unique genes (Mader et al., 2018; Hu et al., 2017; Xu et al., 2017; Yang et al., 2018). Our annotations are similar to those reported above. Comparative analysis indicates that Betulaceae cp genomes possess a set of 113 unique genes, including 79 protein-coding genes, 30 tRNAs, and 4 rRNAs (Table 1). The differences of cp genome size (varying from 159,347 to $160,579 \mathrm{bp}$ ) reflect the genome variation of Betulaceae species. In general, this phenomenon may arise from the contraction and expansion of IR regions, and has been reported in many plant cp genomes (Zhang et al., 2017; Lu et al., 2017). Similarly, despite the conservative property of Betulaceae $\mathrm{cp}$ genomes, changes in the IR/SC junctions were also observed, indicating the $\mathrm{cp}$ genome variation and evolution to some extent.

It has been proved that comparative genomics contributes to the development of divergence hotspots which can be applied for species identification (Ahmed et al., 2013) and phylogenetic studies of different levels (Downie and Jansen, 2015; Shaw et al., 2014). Previous studies have 
358

359

360

361

362

363

364

365

366

367

368

369

370

371

372

373

374

375

376

377

378

379

380

381

382

383

384

385

386

387

388

389

390

391

392

393

394

395

396

397

confirmed that several protein-coding genes of cp genomes were very efficient in resolving the phylogenetic relationships of some complex plant taxa, e.g., petB, rps 16, psaI, rps 11 and rpoA in Notopterygium species (Yang et al., 2017), and $y c f l$ gene in Anemopaegma species (Firetti et al., 2017). Furthermore, more studies reveal that the intergenic spacer regions had higher resolution in species delimitation of related plant taxa, e.g., psaC-ndhE, rpoB-trnC, clpP-psbB, rpl32-trnL, $\operatorname{trn} T-p s b D$, and $\operatorname{ccs} A-n d h D$ had significant genetic divergence among Phalaenopsis species (Shaw et al., 2014), and petD-rpoA, trnT-trnL, trnG-trnM, ycf4-cemA, and rpl32-trnL could be used to identify Veroniceae species (Choi et al., 2016). In this research, both variable percentage and synteny analysis of Betulaceae cp genomes indicate that IGS had higher variation than PCG, from which nine intergenic spacer fragments are identified as divergence hotspots (percentage of variable sites $>20 \%$ ) (Fig. 4B; Table S2). Two protein-coding genes ( $p s a I$ and infA) show higher variable rate (percentage of variable sites $>8 \%$ ) than other genes (Fig. 4A; Table S2). Despite of this, the practical application of these hotspots remains to be verified using methods of population genetics.

Repeated sequences play key roles in cp genome rearrangement, divergence, and evolution, while SSRs are extensively applied in population genetics and molecular identification (Weng et al., 2013; Xue et al., 2012; Guisinger et al., 2010). The presence of repeated sequences in cp genomes, especially in IGS, has been discovered in many known angiosperm lineages (Xue et al., 2012; Xu et al., 2017; Yang et al., 2017). Similarly, we identify four sorts of repeated sequences and six types of SSRs that distribute widely in IGS of the three Betulaceae cp genomes. Moreover, the three $\mathrm{cp}$ genomes present obvious differences in both the distribution pattern and number of dispersed repeats; however, no significant differences are observed in tandem repeats (Fig. 5; Table S3, S4). Notably, C. wangii cp genome contains the most abundant SSRs among the three species although its genome size is the smallest, which can be used as the unique identification for this species. Furthermore, these cpSSRs are rich in thymine or adenine repeats, but rarely contains guanine or cytosine repeats. Similar findings are also discovered in the cpSSRs of other plant taxa such as Scutellaria (Jiang et al., 2017), Salvia (Qian et al., 2013) and Juglans (Hu et al., 2017). These newly developed repeats and SSRs would be helpful for detecting genetic polymorphisms at population level and assessing distantly related evolutionary relationships within Betulaceae.

\section{Evolutionary relationships within Betulaceae}

Betulaceae are a monophyletic family in the order Fagales and are traditionally divided into two main clades, treated as two subfamilies (Coryloideae and Betuloideae) (Forest et al., 2005; Chen et al., 1999). However, the intergeneric relationships within this family are still not clearly resolved because previous phylogenetic conclusions in Betulaceae were inferred either based on morphological characters (Stone, 1973; Abbe, 1974) or several molecular fragments such as chloroplast $m a t K$ gene (Kato et al., 1998), rbcL gene (Bousquet et al., 1992), as well as nuclear ITS sequences (Chen et al., 1999). Compared with those morphological markers and single loci, complete cp genome undoubtedly have more advantages to resolve the phylogenetic problems of Betulaceae lineages. In this research, all the phylogenies inferred from the three datasets (CPG, 
398

399

400

401

402

403

404

405

406

407

408

409

410

411

412

413

414

415

416

417

418

419

420

421

422

423

424

425

426

427

428

429

430

431

432

433

434

435

436

PCG, and IGS) are in favor of the division of Coryloideae and Betuloideae, as well as the same genus composition to previous studies within each subfamily (Fig. 6, S1). Nevertheless, two different topologies occur within Coryloideae, with the most apparent discrepancy consisting in the phylogenetic position of Ostryopsis. The CPG and PCG datasets reveal a close affinity between Ostryopsis and the Carpinus-Ostrya subclade, while Corylus formed sister group to the three genera (Fig. 6A, S1). This kind of generic relationship is in accordance with that inferred from ITS and $r b c$ L phylogenies (Chen et al., 1999; Bousquet et al., 1992). By contrast, the IGS dataset supports a sisterhood between Ostryopsis and Corylus (Fig. 6B), which is identical with the phylogenetic inference of matK sequences (Kato et al., 1998). We infer that the incongruence among different datasets may probably be related with various evolutionary rates of different nucleotide regions, which deserves our further validation.

\section{Divergence history and biogeography}

Betulaceae are suggested to have originated in the late Cretaceous ( 70 Mya) in central China of East Asia (Christenhusz and Byng, 2016; Soltis et al., 2011). Due to the proximity of the Tethys Sea, this region at that time may have belonged to the Mediterranean climate which covered parts of present-day Xinjiang and Tibet until the early Tertiary period. This biogeographic origin is favored by the fact that all the six extant genera and nearly one third of species in Betulaceae are native to this region. Our molecular dating analysis supported Betulaceae to be originated at the end of Cretaceous ( 70.49 Mya), which is very close to the above results. Due to the limited representative species and outgroup used in our analysis, ancestral area reconstruction dose not designate an exact origin region. However, we can confirm that ancestors of extant Betulaceae species were once extensively distributed in Laurasia that covered the present-day Asia, Europe, and North America, from which some species have dispersed into Central America, South America, and North Africa through different island chains. Those intercontinental dispersals are also validated from the biogeography of other angiosperms (Morley, 2003; Sanmartín and Ronquist, 2004). On basis of some morphological characters such as three-flowered cymules, bisexual inflorescences, and staminate flowers, the genus Alnus is suggested to be the earliest to split from the ancestor of the Betulaceae because it preserves certain primitive and unique characters of this family (Chen et al., 1999). Betula appears in some aspects to be transitional between Coryloideae and Alnus, with characters of fruit, cymule, and inflorescence being similar or identical to those of Alnus, while other features are akin to those of Coryloideae. Similarly, Corylus is assigned to be intermediate between Betuloideae and Coryloideae because it possesses some common characters shared with Betula and Alnus, as well as the characters peculiar to Ostryopsis, Carpinus, and Ostrya. Our molecular dating analysis indicates that the divergence order of the six genera is Alnus, Betula, Corylus, Ostryopsis, Ostrya, and Carpinus in sequence, which corresponds consistently with the morphological evolution. On the basis of above analyses, detailed taxon sampling needs to be carried out so as to obtain a biogeographic history of Betulaceae on a large-scale.

\section{CONCLUSIONS}


437 Betulaceae cp genomes are highly conserved in genome organization, gene order, and gene 438 content, indicating low-level genome variation. Sequence divergence in SC is higher than IR, 439 and IGS have higher variation than PCG. Nine IGS regions (ycfl-ndhF, trnG-trnR, trnH-psbA, 440 rps19-rpl2, rps16-trnQ, atpA-atpF, ndhC-trnV, ndhF-rpl32, and rpl32-trnL) may be applied in 441 future population genetics and phylogenetic studies of Betulaceae. The phylogenetic inference 442 supports the division of Betulaceae into two subfamilies: Coryloideae and Betuloideae. 443 Ostryopsis is a transitional genus between Corylus and Carpinus-Ostrya. Alnus and Betula of the 444 Betuloideae differentiate earlier than Corylus, Ostryopsis, Ostrya, and Carpinus of the 445 Coryloideae. More detailed taxon sampling will contribute to the comprehensive phylogenetic 446 study.

\section{ACKNOWLEDGEMENTS}

448

449

450

451

452

453

454

455

456

457

458

459

460

461

462

463

464

465

466

467

468

469

470

471

472

473

474

475

We thank Dr. Xinhui Zou and Wenpan Dong of Institute of botany, the Chinese Academy of Sciences for the help in experiment design and genome sequencing. We also thank Xinming He (Yunnan, China) for providing samples.

\section{REFERENCES}

Abbe EC. 1974. Flowers and inflorescences of the "Amentiferae". The botanical review, 40(2), 159-261.

Ahmed I, Matthews PJ, Biggs PJ, Naeem M, Mclenachan PA, Lockhart PJ. 2013. Identification of chloroplast genome loci suitable for high-resolution phylogeographic studies of Colocasia esculenta (L.) Schott (Araceae) and closely related taxa. Molecular Ecology Resources, 13, 929-937.

Angiosperm Phylogeny Group III (APG III). 2009. An update of the Angiosperm Phylogeny Group classification for the orders and families of flowering plants: APG III. Botanical Journal of the Linnean Society, 161: 105-121.

Angiosperm Phylogeny Group IV (APG IV). 2016. An update of the Angiosperm Phylogeny Group classification for the orders and families of flowering plants: APG IV. Botanical Journal of the Linnean Society, 181: 1-20.

Attigala L, Wysocki WP, Duvall MR, Clark LG. 2016. Phylogenetic estimation and morphological evolution of Arundinarieae (Bambusoideae: Poaceae) based on plastome phylogenomic analysis. Molecular phylogenetics and evolution, 101: 111-121.

Bankevich A, Nurk S, Antipov D, Gurevich AA, Dvorkin M, Kulikov AS, Lesin VM, Nikolenko SI, Pham S, Prjibelski AD, Pyshkin AV, Sirotkin AV, Vyahhi N, Tesler G, Alekseyev MA, Pevzner PA. 2012. SPAdes: a new genome assembly algorithm and its applications to single-cell sequencing. Journal of computational biology, 19(5), 455-477.

Barrett CF, Baker WJ, Comer JR, Conran JG, Lahmeyer SC, Leebens-Mack JH, Li J, Lim GS, Mayfield-Jones DR, Perez L, Medina J, Pires JC, Santos C, Stevenson DW, Zomlefer WB, Davis JI. 2016. Plastid genomes reveal support for deep phylogenetic relationships and extensive rate variation among palms and other commelinid monocots. New Phytologist, 209(2), 855-870. 
476

477

478

479

480

481

482

483

484

485

486

487

488

489

490

491

492

493

494

495

496

497

498

499

500

501

502

503

504

505

506

507

508

509

510

511

512

513

514

Benson G. 1999. Tandem repeats finder: a program to analyze DNA sequences. Nucleic Acids Research. 27, 573-580.

Bouckaert R, Heled J, Kühnert D, Vaughan T, Wu CH, Xie D, Suchard MA, Rambaut A, Drummond AJ. 2014. BEAST 2: A Software Platform for Bayesian Evolutionary Analysis. PLoS Computational Biology, 10(4), e1003537.

Bousquet J, Strauss SH, Li PE. 1992. Complete congruence between morphological and rbcLbased molecular phylogenies in birches and related species (Betulaceae). Molecular Biology and Evolution, 9(6), 1076-1088.

Camacho C, Coulouris G, Avagyan V, Ma N, Papadopoulos J, Bealer K, Madden TL. 2009. BLAST+: architecture and applications. BMC Bioinformatics, 10:421.

Chen ZD. 1991. Pollen morphology of the Betulaceae. Acta Phytotaxonomica Sinica, 29: 464475.

Chen ZD, Manchester SR, Sun HY. 1999. Phylogeny and evolution of the Betulaceae as inferred from DNA sequences, morphology, and paleobotany. American Journal of Botany, 86:1168-1181.

Choi KS, Chung MG, Park S. 2016. The complete chloroplast genome sequences of three Veroniceae species (Plantaginaceae): comparative analysis and highly divergent regions. Frontiers in plant science, 7, 355.

Christenhusz MJ, Byng JW. 2016. The number of known plants species in the world and its annual increase. Phytotaxa, 261(3), 201-217.

Conant GC, Wolfe KH. 2008. GenomeVx: simple web-based creation of editable circular chromosome maps. Bioinformatics, 24, 861-862.

Crane PR. 1989. Early fossil history and evolution of the Betulaceae. Volume 2." Higher Hamamelidae." Systematic Association, 40, 87-116.

Dahlgren R. 1983. General aspects of angiosperm evolution and macrosystematics. Nordic journal of botany, 3(1), 119-149.

Darling AE, Mau B, Perna NT. 2010. Progressive Mauve: multiple genome alignment with gene gain, loss and rearrangement. PLoS ONE, 5:e11147.

Dong WP, Liu H, Xu C, Zuo YJ, Chen ZJ, Zhou SL. 2014. A chloroplast genomic strategy for designing taxon specific DNA mini-barcodes: a case study on ginsengs. BMC genetics, $15: 138$.

Faircloth BC. 2008. Msatcommander: detection of microsatellite repeat arrays and automated, locus-specific primer design. Molecular ecology resources, 8(1), 92-94.

Firetti F, Zuntini AR, Gaiarsa JW, Oliveira RS, Lohmann LG, Van Sluys MA. 2017. Complete chloroplast genome sequences contribute to plant species delimitation: A case study of the Anemopaegma species complex. American Journal of Botany, 104(10), 1493-1509.

Forest F, Savolainen V, Chase MW, Lupia R, Bruneau A, Crane PR, Lavin M. 2005. Teasing apart molecular-versus fossil-based error estimates when dating phylogenetic trees: a case study in the birch family (Betulaceae). Systematic Botany, 30, 118-133. 
515 Furlow JJ. 1990. The genera of Betulaceae in the southeastern United States. Journal of the $516 \quad$ Arnold Arboretum, 71:1-67.

517 Grimm GW, Renner SS. 2013. Harvesting Betulaceae sequences from GenBank to generate a 518 new chronogram for the family. Botanical Journal of the Linnean Society, 172: 465-477.

519 Guindon S, Dufayard JF, Lefort V, Anisimova M, Hordijk W, Gascuel O. 2010. New algorithms 520 and methods to estimate maximum-likelihood phylogenies: assessing the performance of 521 PhyML 3.0. Systematic Biology, 59(3), 307-321.

522 Guisinger MM, Kuehl JV, Boore JL, Jansen RK. 2010. Extreme reconfiguration of plastid

523

524

525

526

527

528

529

530

531

532

533

534

535

536

537

538

539

540

541

542

543

544

545

546

547

548

549

550

551

552

553 genomes in the angiosperm family Geraniaceae: rearrangements, repeats, and codon usage. Molecular Biology and Evolution, 28(1): 583-600.

Hansen DR, Dastidar SG, Cai Z, Penaflor C, Kuehl JV, Boore JL, Jansen RK 2007. Phylogenetic and evolutionary implications of complete chloroplast genome sequences of four earlydiverging angiosperms: Buxus (Buxaceae), Chloranthus (Chloranthaceae), Dioscorea (Dioscoreaceae), and Illicium (Schisandraceae). Molecular phylogenetics and evolution, 45(2): 547-563.

Huang H, Shi C, Liu Y, Mao SY, Gao LZ. 2014. Thirteen Camellia chloroplast genome sequences determined by high-throughput sequencing: genome structure and phylogenetic relationships. BMC Evolution and Biology, 14:151.

Hutchinson J. 1967. The Genera of Flowering Plants Vol-1. Oxford University Press; London.

$\mathrm{Hu}$ Y, Woeste KE, Zhao P. 2017. Completion of the chloroplast genomes of five Chinese Juglans and their contribution to chloroplast phylogeny. Frontiers in plant science, 7:1955.

Jiang D, Zhao Z, Zhang T, Zhong W, Liu C, Yuan Q, and Huang L. 2017. The Chloroplast Genome Sequence of Scutellaria baicalensis Provides Insight into Intraspecific and Interspecific Chloroplast Genome Diversity in Scutellaria. Genes, 8(9), 227.

Kalyaanamoorthy S, Minh BQ, Wong TK, von Haeseler A, Jermiin LS. 2017. ModelFinder: fast model selection for accurate phylogenetic estimates. Nature methods, 14(6), 587.

Kato H, Oginuma K, Gu Z, Hammel B, Tobe H. 1998. Phylogenetic relationships of Betulaceae based on matK sequences with particular reference to the position of Ostryopsis. Acta Phytotaxonomica et Geobotanica, 49(2), 89-97.

Katoh K, Standley DM. 2013. MAFFT multiple sequence alignment Software Version 7: improvements in performance and usability. Molecular biology and evolution, 30(4): 772780.

Kearse1 M, Moir1 R, Wilson A, Stones-Havas S, Cheung M, Sturrock S, Buxton S, Cooper A, Markowitz S, Duran C, Thierer T, Ashton B, Meintjes P, Drummond A. 2012. Geneious Basic: an integrated and extendable desktop software platform for the organization and analysis of sequence data. Bioinformatics, 28(12), 1647-1649.

Kikuzawa K. 1982. Leaf survival and evolution in Betulaceae. Annals of Botany, 50: 345-354.

Kubitzki K, Rohwer JG, Bittrich V. 1993. Flowering Plants, Dicotyledons: Magnoliid, Hamamelid, and Caryophyllid Families. SpringerVerlag, New York, USA. 
554 Kurtz S, Choudhuri JV, Ohlebusch E, Schleiermacher C, Stoye J, Giegerich R. 2001. REPuter:

555

556

557

558

559

560

561

562

563

564

565

566

567

568

569

570

571

572

573

574

575

576

577

578

579

580

581

582

583

584

585

586

587

588

589

590

591

592

593 the manifold applications of repeat analysis on a genomic scale. Nucleic acids research, 29(22), 4633-4642.

Li H, Cao H, Cai YF, Wang JH, Qu SP, Huang XQ. 2014. The complete chloroplast genome sequence of sugar beet (beta vulgaris ssp. vulgaris). Mitochondrial Dna, 25(3), 209. 2014. The complete chloroplast genome sequence of sugar beet (Beta vulgaris ssp. vulgaris). Mitochondrial DNA, 25:209-211

Li J, Wang S, Jing Y, Wang L, Zhou S. 2013. A modified CTAB protocol for plant DNA extraction. Chinese Bulletin of Botany, 48, 72-78.

Librado P, Rozas J. 2009. DnaSP v5: a software for comprehensive analysis of DNA polymorphism data. Bioinformatics, 25(11), 1451-1452.

Liu X, Wang Z, Shao W, Ye Z, Zhang J. 2016. Phylogenetic and taxonomic status analyses of the Abaso section from multiple nuclear genes and plastid fragments reveal new insights into the North America origin of Populus (Salicaceae). Frontiers in plant science, 7, 2022.

Lu RS, Li P, Qiu, YX. 2017. The complete chloroplast genomes of three Cardiocrinum (Liliaceae) species: comparative genomic and phylogenetic analyses. Frontiers in plant science, 7, 2054.

Mader M, Pakull B, Blanc-Jolivet C, Paulini-Drewes M, Bouda ZHN, Degen B, Small I, Kersten B. 2018. Complete Chloroplast Genome Sequences of Four Meliaceae Species and Comparative Analyses. International journal of molecular sciences, 19(3), 701.

Minh BQ, Nguyen MA. Haeseler A. 2013. Ultrafast approximation for phylogenetic bootstrap. Molecular biology and evolution, 30(5), 1188-1195.

Morley RJ. 2003. Interplate dispersal paths for megathermal angiosperms. Perspectives in Plant Ecology, Evolution and Systematics, 6(1-2), 5-20.

Nazareno AG, Carlsen M, Lohmann LG. 2015. Complete chloroplast genome of Tanaecium tetragonolobum: the first Bignoniaceae plastome. PLoS One, 10(6), e0129930.

Nguyen LT, Schmidt HA, Von Haeseler A, Minh BQ. 2015. IQ-TREE: a fast and effective stochastic algorithm for estimating maximum-likelihood phylogenies. Molecular biology and evolution, 32(1), 268-274.

Olsen JL, Rouzé P, Verhelst B, Lin YC, Bayer T, Collen J, Dattolo E, Paoli ED, Dittami S, Maumus F, Michel G, Kersting A, Lauritano C, Lohaus R, Töpel M, Tonon T, Vanneste K, Amirebrahimi M, Brakel J, Boström C, Chovatia1 M, Grimwood J, Jenkins JW, Jueterbock A, Mraz A, Stam WT, Tice H, Bornberg-Bauer E, Green PJ, Pearson GA, Procaccini G, Duarte CM, Schmutz J, Reusch TBH, Peer YVD. 2016. The genome of the seagrass Zostera marina reveals angiosperm adaptation to the sea. Nature, 530(7590): 331.

Palmer JD, Herbon LA. 1988. Plant mitochondrial DNA evolved rapidly in structure, but slowly in sequence. Journal of Molecular Evolution. 28, 87-97.

Philippe H, Brinkmann H, Lavrov DV, Littlewood DT, Manuel M, Wörheide G, Baurain D. 2011. Resolving difficult phylogenetic questions: why more sequences are not enough. PLOS Biology, 9:e1000602. 
594 Pigg KB, Manchester SR, Wehr WC. 2003. Corylus, Carpinus, and Palaeocarpinus (Betulaceae)

595

596

597

598

599

600

601

602

603

604

605

606

607

608

609

610

611

612

613

614

615

616

617

618

619

620

621

622

623

624

625

626

627

628

629

630

631

632 from the middle Eocene Klondike Mountain and Allenby formations of northwestern North America. International Journal of Plant Sciences, 164(5), 807-822.

Provan J, Powell W, Hollingsworth PM. 2001. Chloroplast microsatellites: new tools for studies in plant ecology and evolution. Trends in ecology and evolution, 16(3), 142-147.

Qian J, Song JY, Gao HH, Zhu YJ, Xu J, Pang XH, Yao H, Sun C, Li XE, Li CY, Liu JY, Xu HB, Chen SL. 2013. The complete chloroplast genome sequence of the medicinal plant Salvia miltiorrhiza. PLoS ONE 8:e57607.

Raman G, Park S. 2016. The complete chloroplast genome sequence of Ampelopsis: gene organization, comparative analysis, and phylogenetic relationships to other angiosperms. Frontiers in plant science, 7, 341.

Rambaut A. 1996. Se-Al Version 2.0a11 [Computer Program]. Available from: http://tree.bio.ed.ac.uk/software/seal/.

Rambaut A, Drummond AJ. 2009. Tracer v1.5 [WWW document]. URL http://evolve.zoo.ox.ac.uk/software.html.

Rambaut A. 2012. FigTree v1. 4. University of Edinburgh, Edinburgh, UK Available at: http://tree bio ed ac uk/software/figtree.

Ronquist F, Teslenko M, Van Der Mark P, Ayres DL, Darling A, Höhna S, Larget B, Liu L, Suchard MA, Huelsenbeck JP. 2012. MrBayes 3.2: efficient Bayesian phylogenetic inference and model choice across a large model space. Systematic biology, 61(3), 539-542.

Sanmartin I, Ronquist F. 2004. Southern hemisphere biogeography inferred by event-based models: plant versus animal patterns. Systematic biology, 53(2), 216-243.

Schattner P, Brooks AN, Lowe TM. 2005. The tRNAscan-SE, snoscan and snoGPSweb servers for the detection of tRNAs and snoRNAs. Nucleic Acids Research, 33, W686-W689.

Shaw J, Lickey EB, Beck JT, Farmer SB, Liu W, Miller J, Siripun KC, Winder CT, Schilling EE, Small RL. 2005. The tortoise and the hare II: relative utility of 21 noncoding chloroplast DNA sequences for phylogenetic analysis. American Journal of Botany, 92, 142-166.

Shaw J, Shafer HL, Leonard OR, Kovach MJ, Schorr M, Morris AB. 2014. Chloroplast DNA sequence utility for the lowest phylogenetic and phylogeographic inferences in angiosperms: the tortoise and the hare IV. American Journal of Botany, 101(11): 19872004.

Soltis DE, Smith SA, Cellinese N, Wurdack KJ, Tank DC, Brockington SF, Refulio-Rodriguez NF, Walker JB, Moore MJ, Carlsward BS, Bell CD, Latvis M, Crawley S, Black C, Diouf D, Xi Z, Rushworth CA, Gitzendanner MA, Sytsma KJ, Qiu YL, Hilu KW, Davis CC, Sanderson MJ, Beaman RS, Olmstead RG, Judd WS, Donoghue MJ, Soltis PS. 2011. Angiosperm phylogeny: 17 genes, 640 taxa. American journal of botany, 98(4), 704-730.

Stone DE. 1973. Patterns in the evolution of amentiferous fruits. Brittonia, 25(4), 371-384.

Talavera G, Castresana J. 2007. Improvement of phylogenies after removing divergent and ambiguously aligned blocks from protein sequence alignments. Syst. Biol. 56, 564-577. 
633 Walker JF, Zanis MJ, Emery NC. 2014. Comparative analysis of complete chloroplast genome

634

635

636

637

638

639

640

641

642

643

644

645

646

647

648

649

650

651

652

653

654

655

656

657

658

659

660

661

662

663

664

665

666

667

668

669

670

671

672 sequence and inversion variation in Lasthenia burkei (Madieae, Asteraceae). American journal of botany, 101(4), 722-729.

Wang W, Haberer G, Gundlach H, Gläßer C, Nussbaumer T, Luo MC, Lomsadze A, Borodovsky M, Kerstetter RA, Shanklin J, Byrant DW, Mockler TC, Appenroth KJ, Grimwood J, Jenkins J, Chow J, Choi C, Adam C, Cao XH, Fuchs J, Schubert I, Rokhsar D, Schmutz J, Michael TP, Mayer KF, Messing J. 2014. The Spirodela polyrhiza genome reveals insights into its neotenous reduction fast growth and aquatic lifestyle. Nature Communications, 5: ncomms4311.

Weng ML, Blazier JC, Govindu M, Jansen RK. 2013. Reconstruction of the ancestral plastid genome in Geraniaceae reveals a correlation between genome rearrangements, repeats and nucleotide substitution rates. Molecular Biology and Evolution, 31, 645-659.

Wyman SK, Jansen RK, Boore JL. 2004. Automatic annotation of organellar genomes with DOGMA. Bioinformatics, 20, 3252-3255.

Xiang XG, Wang W, Li RQ, Lin L, Liu Y, Zhou ZK, Li ZY, Chen ZD. 2014. Large-scale phylogenetic analyses reveal fagalean diversification promoted by the interplay of diaspores and environments in the Paleogene. Perspectives in Plant Ecology, Evolution and Systematics, 16(3), 101-110.

Xing SP, Chen ZD, Lu AM. 1998. Development of ovule and embryo sac in Ostrya virginiana (Betulaceae) and its systematic significance. Acta Phytotaxonomica Sinica, 36: 428-435.

Xu C, Dong W, Li W, Lu Y, Xie X, Jin X, Shi J, He K, Suo Z. 2017. Comparative analysis of six Lagerstroemia complete chloroplast genomes. Frontiers in plant science, 8:15.

Xue J, Wang S, Zhou SL. 2012. Polymorphic chloroplast microsatellite loci in Nelumbo (Nelumbonaceae). American journal of botany, 99(6).

Yang J, Vázquez L, Chen X, Li H, Zhang H, Liu Z, Zhao G. 2017. Development of chloroplast and nuclear DNA markers for Chinese oaks (Quercus subgenus Quercus) and assessment of their utility as DNA barcodes. Frontiers in plant science 8:816.

Yang Z, Zhao T, Ma Q, Liang L, Wang G. 2018. Comparative Genomics and Phylogenetic Analysis Revealed the Chloroplast Genome Variation and Interspecific relationships of Corylus (Betulaceae) Species. Frontiers in Plant Science, 9, 927.

Yoo KO, Wen J. 2002. Phylogeny and biogeography of Carpinus and subfamily Coryloideae (Betulaceae). International Journal of Plant Sciences, 163(4): 641-650.

Yu Y, Harris AJ, Blair C, He X. 2015. RASP (Reconstruct Ancestral State in Phylogenies): a tool for historical biogeography. Molecular phylogenetics and evolution, 87, 46-49.

Zhang SD, Jin JJ, Chen SY, Chase MW, Soltis DE, Li HT, Yang JB, Li DZ, Yi TS. 2017. Diversification of Rosaceae since the Late Cretaceous based on plastid phylogenomics. New Phytologist, 214(3), 1355-1367.

Zhang Y, Du L, Liu A, Chen J, Wu L, Hu W, Zhang W, Kim K, Lee SC, Yang TJ, Wang Y. 2016. The complete chloroplast genome sequences of five Epimedium species: lights into phylogenetic and taxonomic analyses. Frontiers in plant science, 7, 306. 


\section{Figure 1}

The genome maps of three Betulaceae chloroplast genomes.

The genes outside and inside of the circle are transcribed in the counterclockwise and clockwise directions, respectively. Different colors indicate the genes belonging to different functional groups. The thicknesses denote the extent of IRs (IRa and IRb) that separate the cp genomes into LSC and SSC regions. 


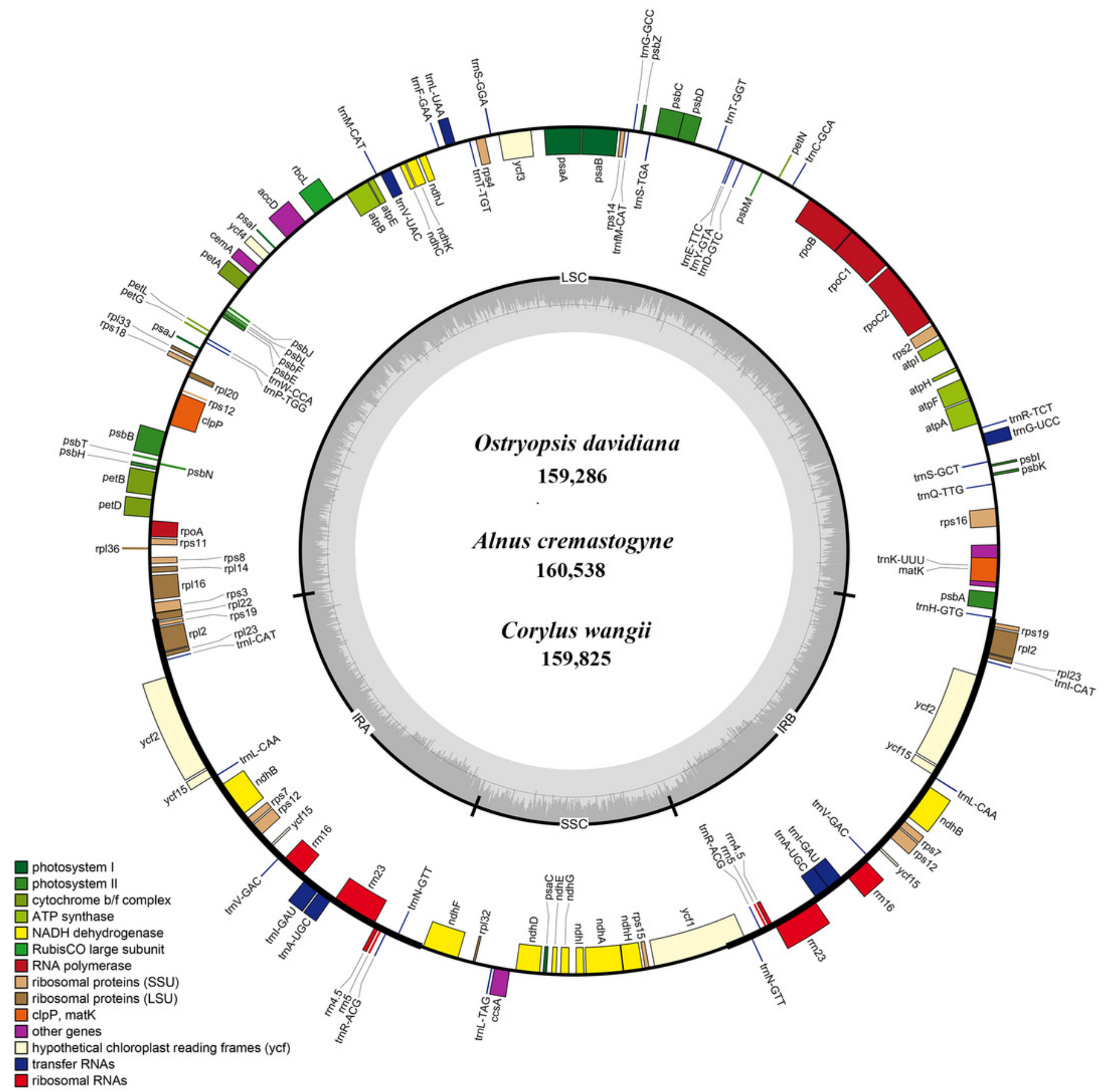




\section{Figure 2}

\section{Comparison of the border positions of LSC, IR and SSC among the six Betulaceae} chloroplast genomes.

Ostryopsis davidiana

$159,286 \mathrm{bp}$

Alnus cremastogyne

$160,538 \mathrm{bp}$

Corylus wangii

$159,825 \mathrm{bp}$

Carpinus tientaiensis

160,104 bp

\section{Betula nana}

$160,579 \mathrm{bp}$

Ostrya rehderiana

$159,347 \mathrm{bp}$

\begin{tabular}{|c|c|c|c|c|c|c|c|}
\hline \begin{tabular}{r|}
$272 \mathrm{bp}$ \\
$r p s 19$ \\
\end{tabular} & $3 \mathrm{bp}$ & $\begin{array}{c}1192 \mathrm{bp} \\
y c f 1\end{array}$ & $1 \mathrm{bp}$ & $\begin{array}{r}4515 \mathrm{bp} \\
y c f 1 \\
\end{array}$ & 1193 bp & $\frac{71 \mathrm{bp}}{r p l 2}$ & $\frac{10 \mathrm{bp}}{t r n H}$ \\
\hline LSC & \multicolumn{2}{|c|}{$\mathrm{IRa}$} & \multicolumn{2}{|c|}{$\mathrm{SSC}$} & \multicolumn{2}{|c|}{$\mathrm{IRb}$} & LSC \\
\hline $88,568 \mathrm{bp}$ & \multicolumn{2}{|c|}{$26,065 \mathrm{bp}$} & \multicolumn{2}{|c|}{$18,588 \mathrm{bp}$} & \multicolumn{2}{|c|}{$26,065 \mathrm{bp}$} & $88,568 \mathrm{bp}$ \\
\hline$\frac{32 \mathrm{bp}}{\text { rps } 19}$ & $\int \frac{82 b p}{r p l 2}$ & ycf1 & $\begin{array}{l}23 \mathrm{bp} \\
\boldsymbol{n d h} \boldsymbol{F}\end{array}$ & $\begin{array}{r}4460 \mathrm{bp} \\
y c f 1\end{array}$ & $1296 \mathrm{bp}$ & $\frac{82 \mathrm{bp}}{r p l 2}$ & $\frac{1 \mathrm{bp}}{t r n H}$ \\
\hline LSC & \multicolumn{2}{|c|}{ IRa } & \multicolumn{2}{|c|}{$\mathrm{SSC}$} & \multicolumn{2}{|c|}{$\mathrm{IRb}$} & LSC \\
\hline 89,074 bp & \multicolumn{2}{|c|}{$26,185 \mathrm{bp}$} & \multicolumn{2}{|c|}{19,094 bp } & \multicolumn{2}{|c|}{$26,185 \mathrm{bp}$} & $89,074 \mathrm{bp}$ \\
\hline rps19 & $8 \mathrm{bp}$ & \multirow[t]{2}{*}{$\begin{array}{c}4 \mathrm{bp} \\
y c f 1\end{array}$} & \multicolumn{2}{|c|}{$\begin{array}{l}119 \mathrm{bp} \\
\boldsymbol{n} \boldsymbol{d h \boldsymbol { h }}\end{array}$} & $1213 \mathrm{bp}$ & $\begin{array}{l}77 \mathrm{bpw} \\
\mathrm{rppl} 2\end{array}$ & $\frac{3 \mathrm{bp}}{t r n H}$ \\
\hline LSC & \multirow{2}{*}{\multicolumn{2}{|c|}{ IRa }} & \multicolumn{2}{|c|}{ SSC } & \multicolumn{2}{|c|}{$\mathrm{IRb}$} & LSC \\
\hline 88,743 bp & & & \multicolumn{2}{|c|}{$18,870 \mathrm{bp}$} & \multicolumn{2}{|c|}{$26,106 \mathrm{bp}$} & $88,743 \mathrm{bp}$ \\
\hline $\begin{aligned} 1 \text { bps } \\
\text { rps19 }\end{aligned}$ & $\int_{r p l 2}^{72 b p}$ & $\begin{array}{l}1157 \mathrm{bp} \\
y c f 1\end{array}$ & $3 \mathrm{bp}$ & \begin{tabular}{r|}
$4548 \mathrm{bp}$ \\
$y c f 1$
\end{tabular} & 1157 bp & $\frac{72 \mathrm{bp}}{r p l 2}$ & $\overbrace{\text { trnH }}^{88 \mathrm{bp}}$ \\
\hline LSC & \multicolumn{2}{|c|}{$\mathrm{IRa}$} & \multicolumn{2}{|c|}{$\mathrm{SSC}$} & \multicolumn{2}{|c|}{$\mathrm{IRb}$} & LSC \\
\hline 89,446 bp & \multicolumn{2}{|c|}{$26,030 \mathrm{bp}$} & \multicolumn{2}{|c|}{$18,598 \mathrm{bp}$} & \multicolumn{2}{|c|}{$26,030 \mathrm{bp}$} & $89,446 \mathrm{bp}$ \\
\hline $\begin{array}{r}6 \mathrm{bpp} \\
r p s 19\end{array}$ & $\overbrace{r p l 2}^{72 b p}$ & $\begin{array}{r}1236 \mathrm{bp} \\
y c f 1\end{array}$ & $155 \mathrm{bp}$ & $\begin{array}{r}4511 \mathrm{bp} \\
y c f 1 \\
\end{array}$ & $1236 \mathrm{bp}$ & $\begin{array}{l}72 \mathrm{bph} \\
r p l 2\end{array}$ & trnH \\
\hline LSC & \multicolumn{2}{|c|}{ IRa } & \multicolumn{2}{|c|}{ SSC } & \multicolumn{2}{|c|}{$\mathrm{IRb}$} & LSC \\
\hline $89,493 \mathrm{bp}$ & \multicolumn{2}{|c|}{$26,034 \mathrm{bp}$} & \multicolumn{2}{|c|}{19,018 bp } & \multicolumn{2}{|c|}{$26,034 \mathrm{bp}$} & $89,493 \mathrm{bp}$ \\
\hline $\begin{array}{r}331 \mathrm{bp} \\
r p l 2 \\
\end{array}$ & $156 \mathrm{bp}$ & veft & \begin{tabular}{|l|}
$2165 \mathrm{bp}$ \\
$\boldsymbol{n d h \boldsymbol { h }}$ \\
\end{tabular} & $\begin{array}{r}4769 \mathrm{bp} \\
y c f 1\end{array}$ & $951 \mathrm{bp}$ & rpl2 & trnH \\
\hline LSC & & & & & & & LSC \\
\hline $88,552 \mathrm{bp}$ & & & & & 25 , & & 88,552 bp \\
\hline
\end{tabular}


Figure 3

Synteny and rearrangements detected in six Betulaceae chloroplast genomes using the Mauve multiple-genome alignment program.

Color plots reflect the level of sequence similarity, and lines linking blocks with the same color represent homology between two genomes. Ruler above each genome indicates nucleotide positions, and white regions indicate element specific to a genome. The above and below gene blocks are transcribed clockwise and transcribed counterclockwise, respectively.

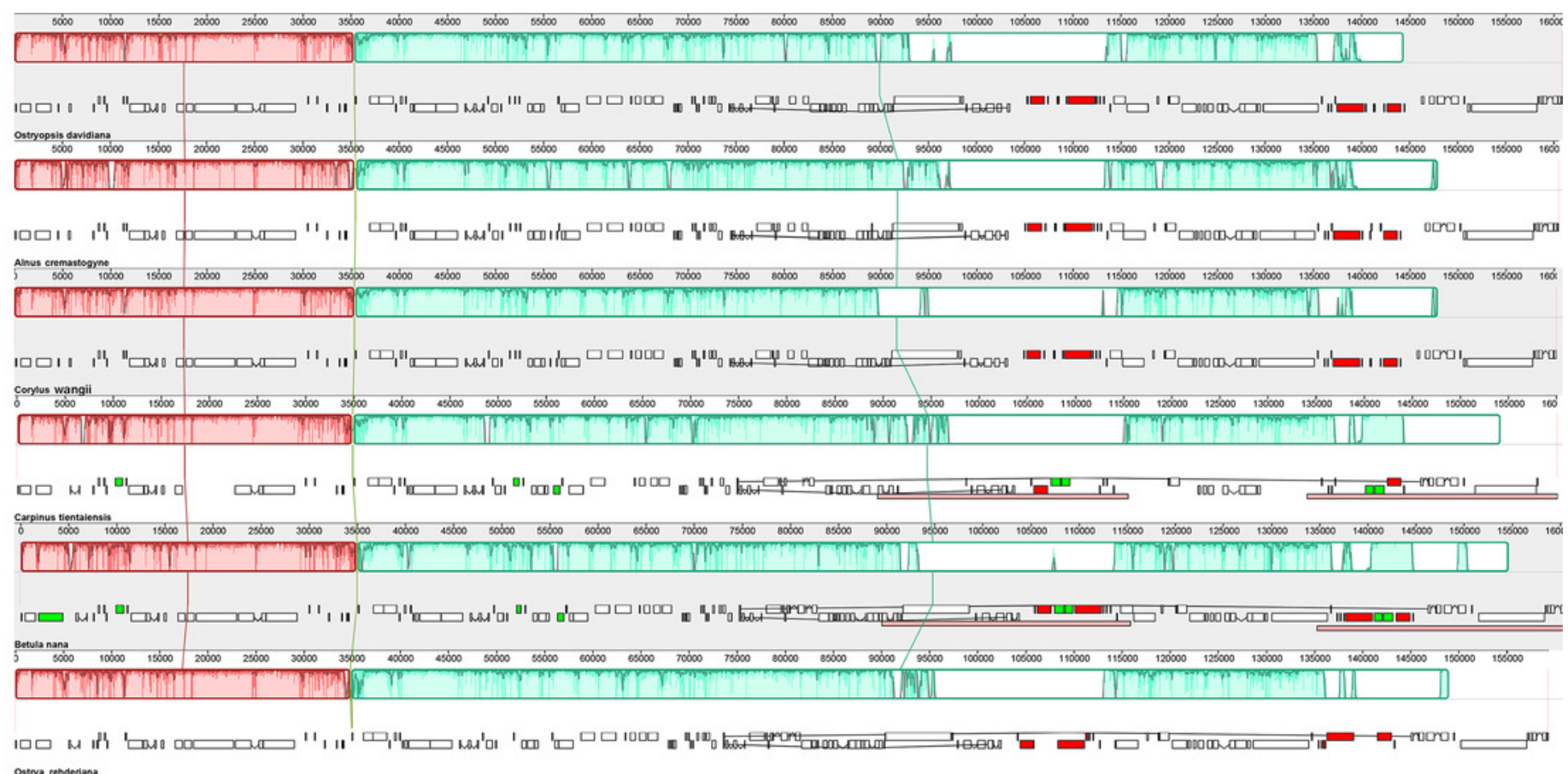




\section{Figure 4}

Percentages of variable sites in homologous regions across the six Betulaceae chloroplast genomes.

(A) Protein-coding regions, (B) intergenic spacer regions.
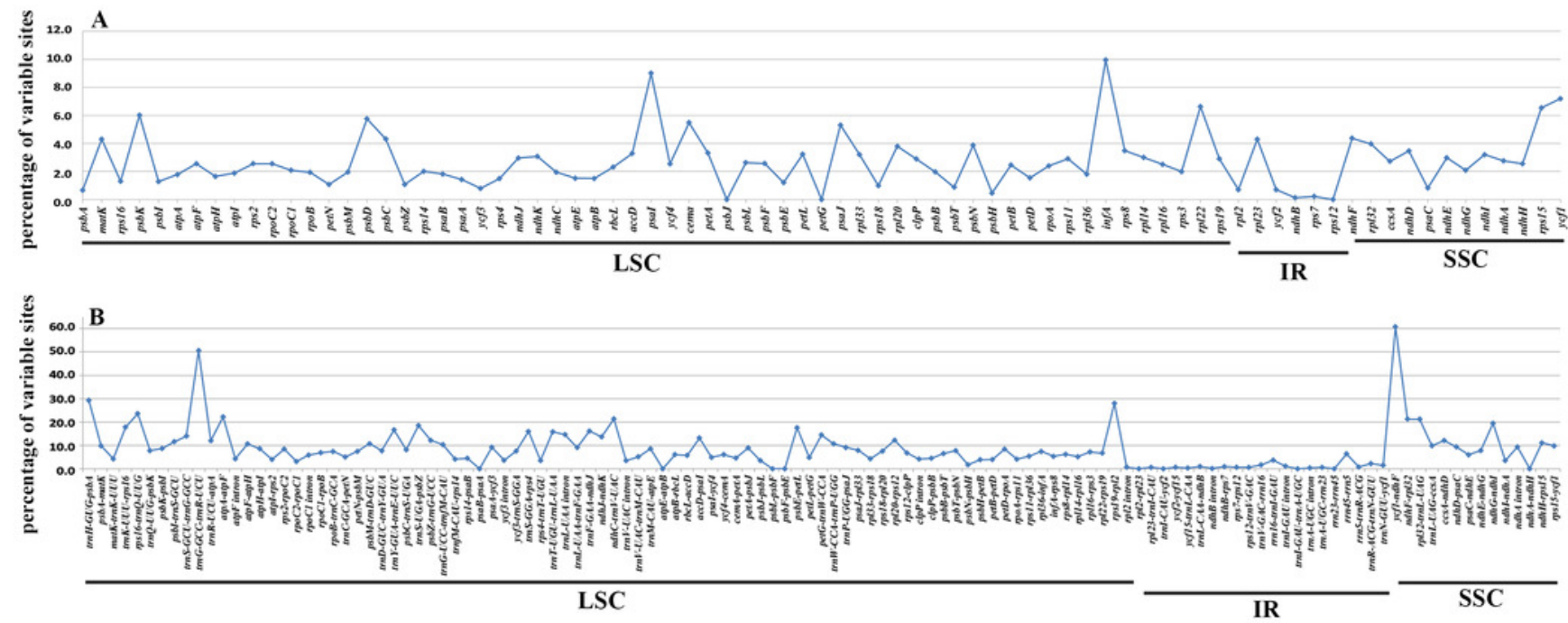
Figure 5

Analyses of repeated sequences and SSRs in the three Betulaceae chloroplast genomes.

(A) Frequency of repeated sequences by length, (B) Frequency of four repeat types, (C)

Frequency of SSR motifs in different repeat class types, (D) Frequency of six SSR types.
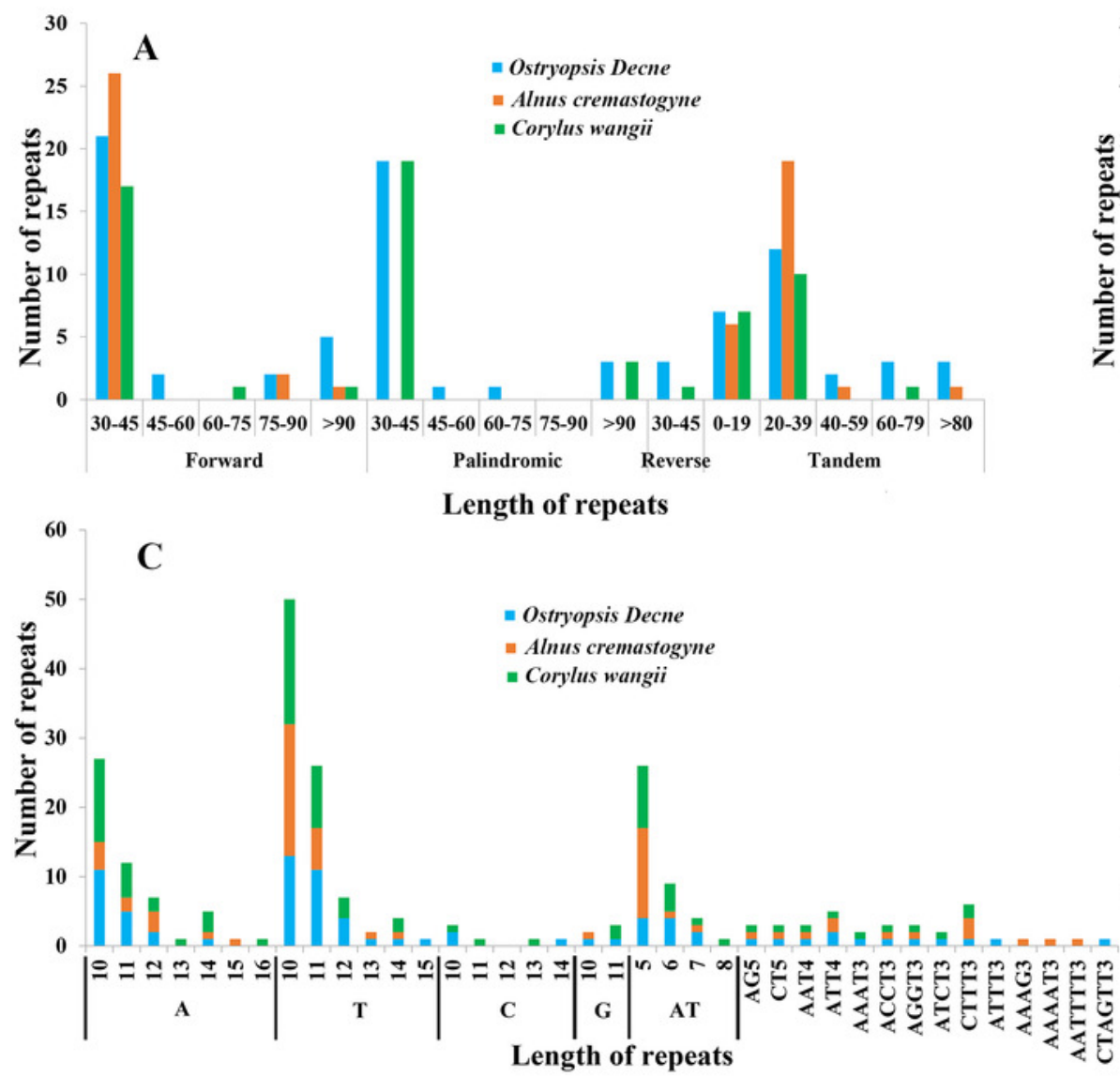
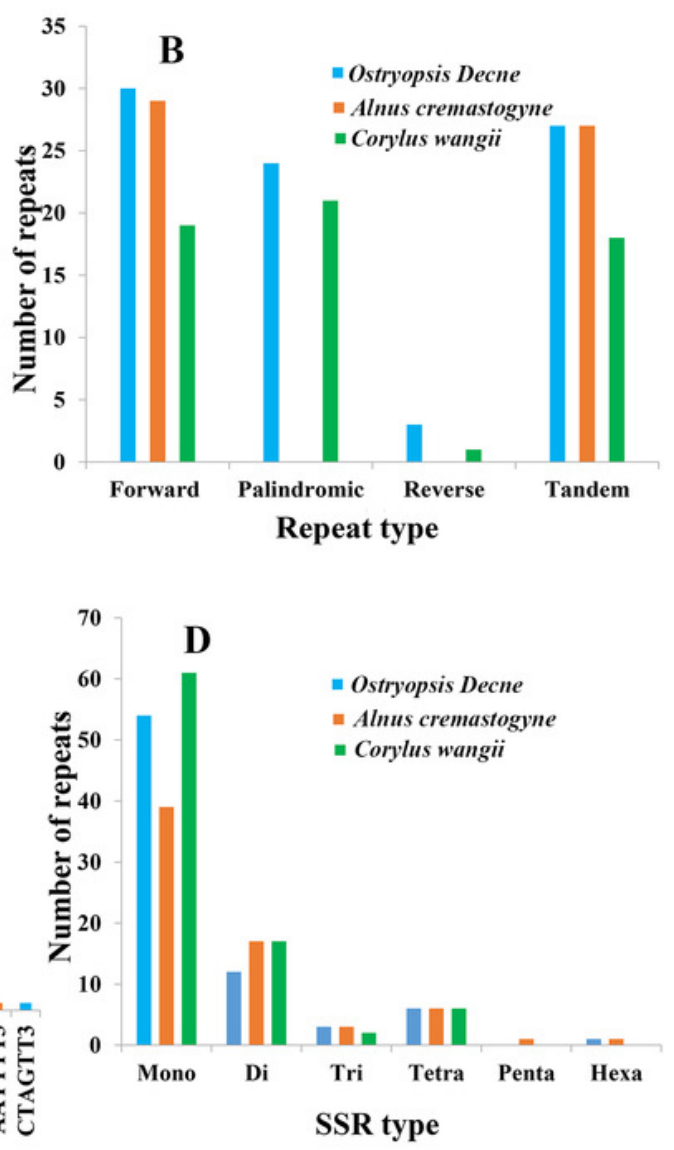


\section{Figure 6}

Phylogenetic trees of Betulaceae as inferred from two data partitions using $\mathrm{ML}$ and $\mathrm{BI}$ methods.

(A) complete cp genome sequences (CPG), (B) intergenic spacer regions (IGS). Support values of ML-SH-Alrt, ML-UFBoot and BI-PP are successively listed above the branches (SHaLRT/UFBoot/PP). 


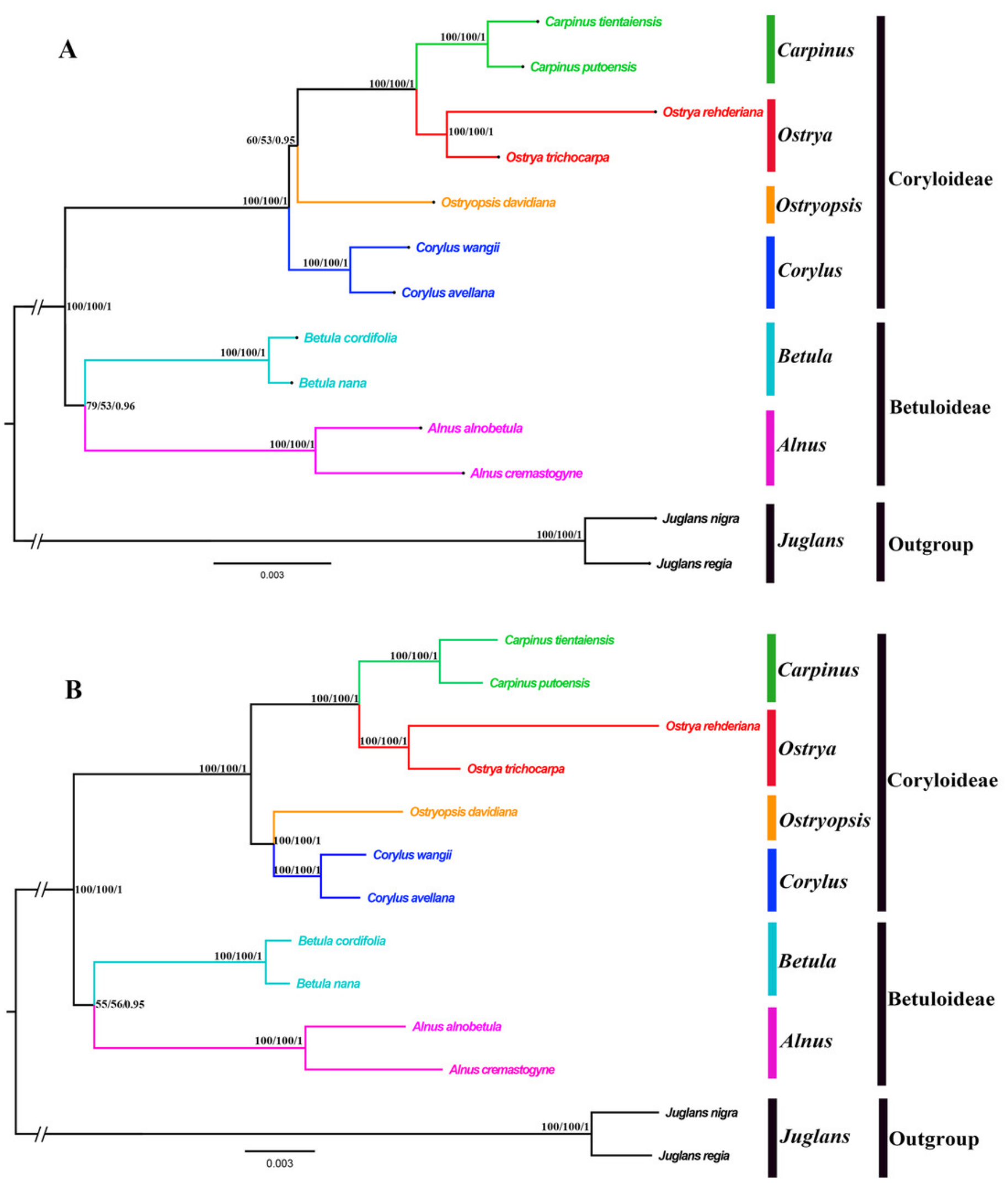




\section{Figure 7}

Fossil-calibrated phylogeny generated by BEAST using an uncorrelated relaxed clock.

Blue bars on the nodes indicate $95 \%$ highest posterior density. Divergence time of clades and subclades are displayed on the branches.

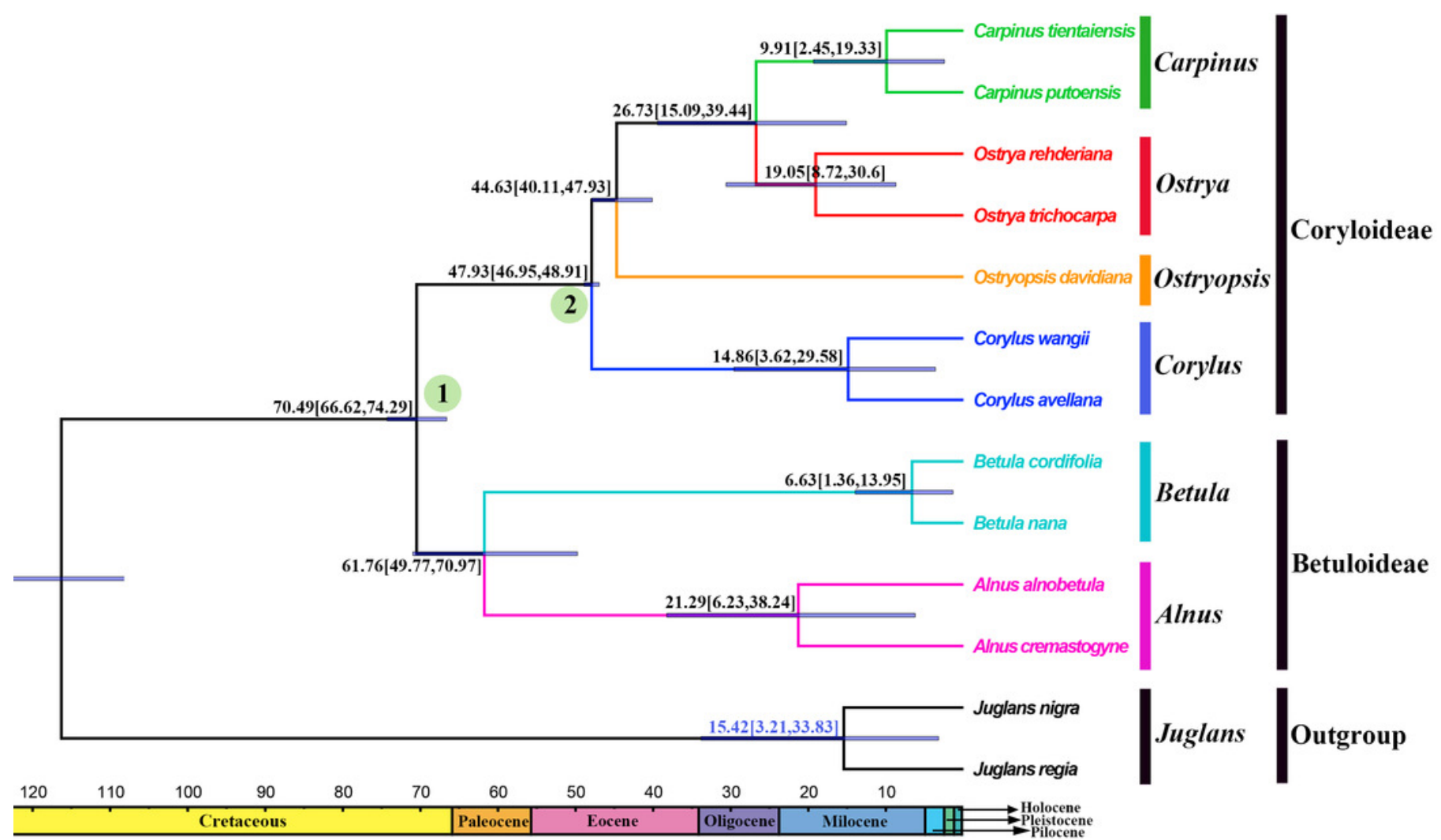




\section{Figure 8}

Ancestral area reconstruction based on the BBM method in RASP.

(A) The insert map shows the contemporary distribution of Betulaceae species, covering six major floristic divisions (1-6). (B) Pie charts on each node of the tree indicate marginal probabilities for each alternative ancestral area. Numbers and colors in the legend refer to extant and possible ancestral areas, and combinations of these.
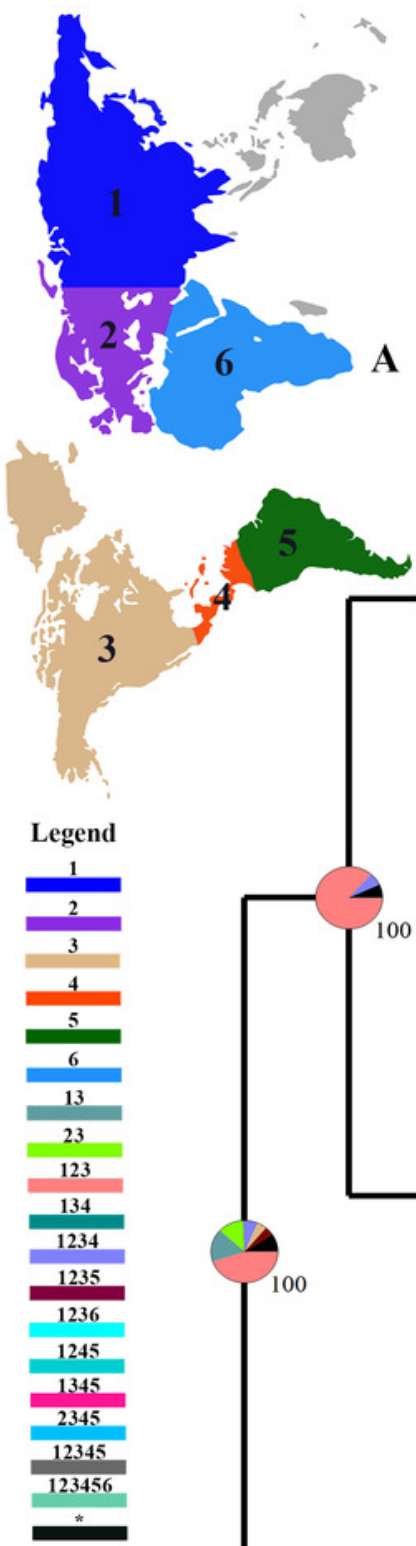

(1)
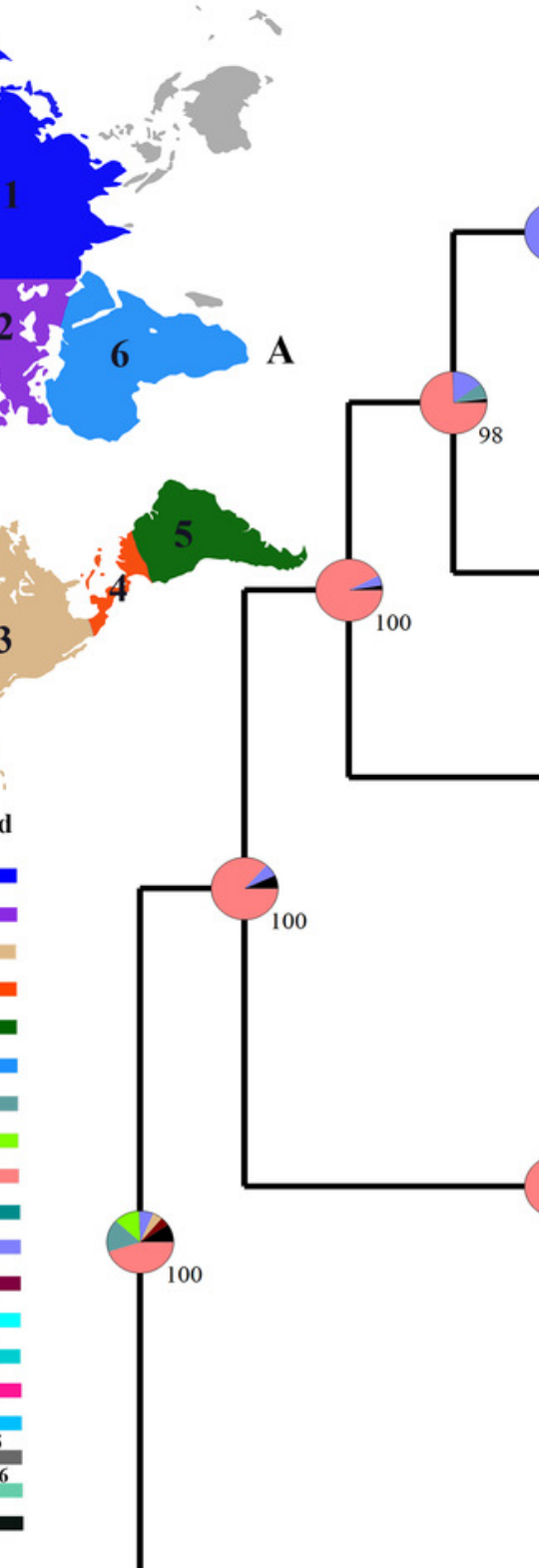

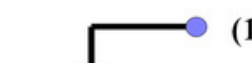

(1234)Carpinus tientaiensis

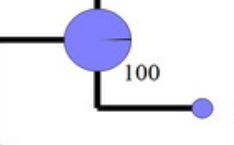

(1234)Carpinus putoensis

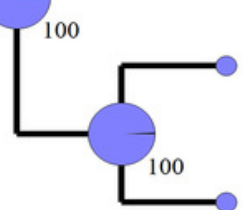

(1234)Ostrya rehderiana

1234)Ostrya rehderiana

(1234)Ostrya trichocarpa

(1)Ostryopsis davidiana

(123)Corylus wangii

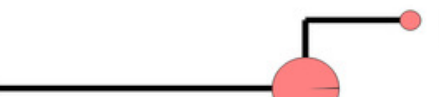

(123)Corylus avellana

(123)Betula cordifolia
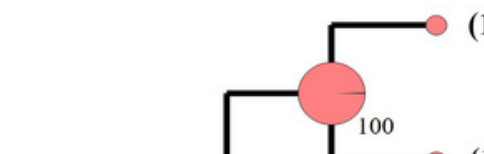

(123)Betula nana

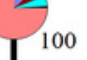

(123456)Alnus alnobetula

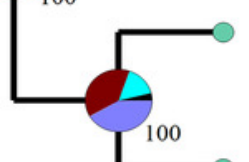

(123456)Alnus alnobetula

(123456)Alnus cremastogyne

(12345)Juglans nigra 


\section{Table $\mathbf{1}$ (on next page)}

Comparison of the chloroplast genome organization among six Betulaceae species. 
1 Table 1 Comparison of the chloroplast genome organization among six Betulaceae species.

\begin{tabular}{|c|c|c|c|c|c|c|c|c|c|}
\hline Taxon & Size (bp) & LSC (bp) & SSC (bp) & IR (bp) & $\begin{array}{l}\text { Total } \\
\text { genes }\end{array}$ & $\begin{array}{c}\text { Protein } \\
\text { coding genes }\end{array}$ & $\begin{array}{l}\text { tRNA } \\
\text { genes }\end{array}$ & $\begin{array}{l}\text { rRNA } \\
\text { genes }\end{array}$ & $\begin{array}{c}\text { GC content } \\
(\%)\end{array}$ \\
\hline Ostryopsis davidiana & 159,286 & 88,568 & 18,588 & 26,065 & $131(18)$ & $86(7)$ & $37(7)$ & $8(4)$ & 36.39 \\
\hline Alnus cremastogyne & 160,538 & 89,074 & 19,094 & 26,185 & $131(18)$ & $86(7)$ & $37(7)$ & $8(4)$ & 36.68 \\
\hline Corylus wangii & 159,825 & 88,743 & 18,870 & 26,106 & $131(18)$ & $86(7)$ & $37(7)$ & $8(4)$ & 36.52 \\
\hline Carpinus tientaiensis & 160,104 & 89,446 & 18,598 & 26,030 & $131(18)$ & $86(7)$ & $37(7)$ & $8(4)$ & 36.38 \\
\hline Betula nana & 160,579 & 89,493 & 19,018 & 26,034 & $131(18)$ & $86(7)$ & $37(7)$ & $8(4)$ & 36.07 \\
\hline Ostrya rehderiana & 159,347 & 88,552 & 18,941 & 25,927 & $131(18)$ & $86(7)$ & $37(7)$ & $8(4)$ & 36.46 \\
\hline
\end{tabular}


Table 2 (on next page)

List of genes encoded in the chloroplast genomes of six Betulaceae species. 
Table 2 List of genes encoded in the chloroplast genomes of six Betulaceae species.

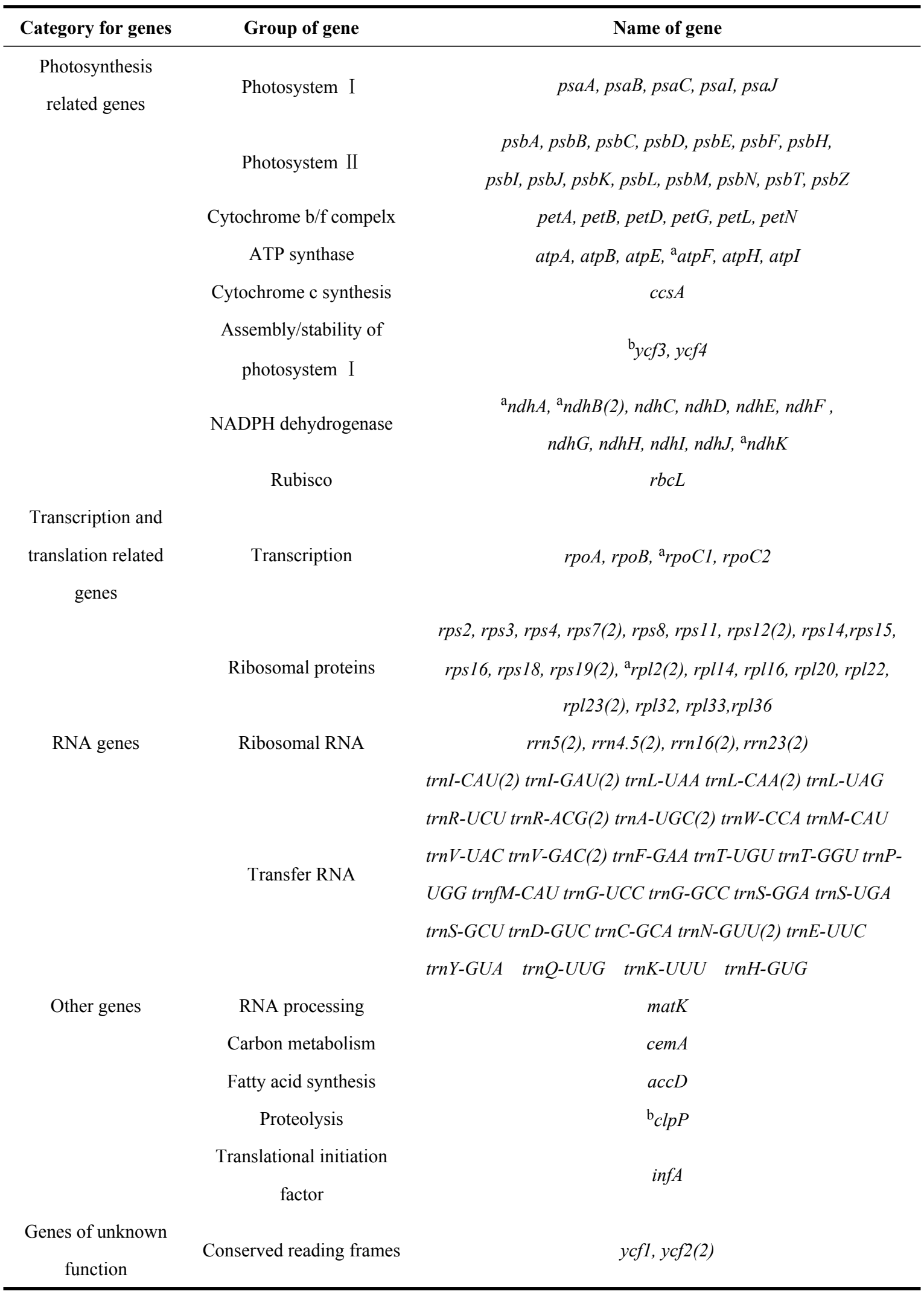

2 a: gene with one intron; b: gene with two introns; (2): gene with two copies 
